EGG-PHY-9615

March 1991

\title{
THE INEL BERYLLIUM MULTIPLICATION EXPERIMENT
} FINAL REPORT

\section{ingineering}

\section{saboratory}
Managed
by the U.S.
lepartment
of Energy
J. R. Smith
J. J. King

NOV 221991
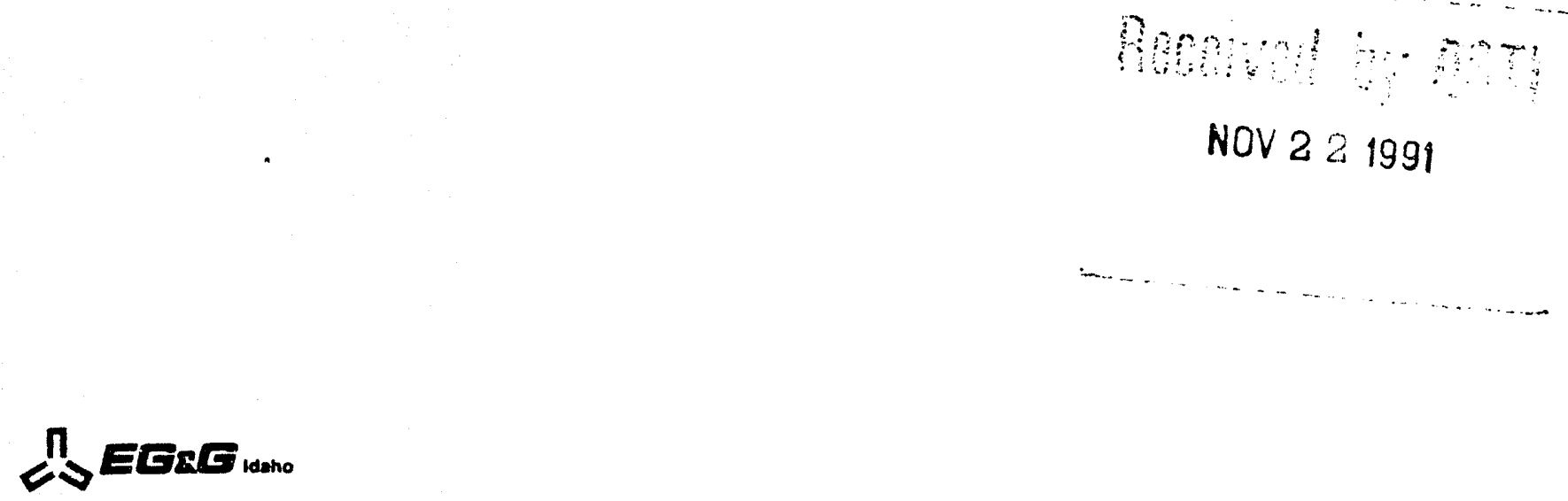

\footnotetext{
Work performed under
DOE Contract No. DE-AC07-76IDO1570
} 
This document contains new concepts or the author(s) interpretation of new calculations and/or measurements; accordingly, EG\&G Idaho, Inc. is reçuired by the United States Government to include the following disclaimer:

\section{DISCLAIMER}

This report was prepared as an account of work sponsored by an agency of the United States Government. Neither the United States Government nor any agency thereof, nor any of their employees, makes any warranty, express or implied, or assumes any legal liability or responsibility for the accuracy, completeness, or usefulness of any information, apparatus, product or process disclosed. or represents that its use would not infringe privately owned rights. References herein to any specific commercial product, process, or service by trade name, trademark, manufacturer, or otherwise, does not necessarily constitute or imply its endorsement, recommendation, or favoring by the United States Government or any agency thereof. The views and opinions of authors expressed herein do not necessarily state or reflect those of the United States Government or any agency thereof. 
EGG-FHY--9615

DE92 003337

THE INEL BERYLLIUM MULTIPLICATION EXPERIMENT FINAL REPORT

\author{
J. Richard Smith \\ John J. King \\ EG\&G Idaho, Inc. \\ Idaho National Engineering Laboratory \\ Idaho Falls, Idaho 83415-7113
}

March 1991

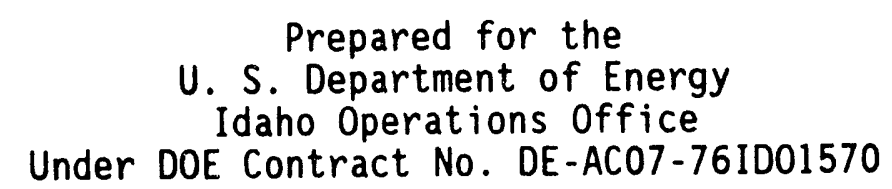


The experiment to measure the multiplication of $14-\mathrm{MeV}$ neutrons in bulk beryllium has been completed. The experiment consists of determining the ratio of ${ }^{56} \mathrm{Mn}$ activities induced in a large manganese bath by a central $14-\mathrm{MeV}$ neutron source, with and without a beryllium sample surrounding the source. The superior isotropy and flat energy response of the manganese bath gives this detector an advantage over the inhomogeneous and anisotropic detector arrays used in previous experiments for measurements of this type. Values of the multiplication have been obtained for beryllium samples of four thicknesses. For beryllium thicknesses of $4.6,12.1,15.6$, and $19.9 \mathrm{~cm}$ the apparent multiplication values are $1.390,1.928,2.072$, and 2.127, respectively. These values are affected by several systematic effects characteristic of the manganese bath. The values of these systematic corrections are established by a combination of calculation and experimental parameterization. The corrected net multiplication values for pure beryllium are $1.311,1.764,1.904$, and 1.988 , respectively. Detailed calculations of the multiplication and all the systematic effects were made with the Monte Carlo program MCNP, utilizing both the Young and Stewart and the ENDF/B-VI evaluations for beryllium. Both data sets produce multiplication values that are in excellent agreement with the measurements for both raw and corrected values of the multiplication. We conclude that there is no real discrepancy between experimental and calculated values for the multiplication of neutrons in bulk beryllium. 


\section{ACKNOWLEDGMENTS}

We would like to express our appreciation to Darrell Reeder, Brian Schuetz, and $A l a n$ Johnson for their work on the chemical characterization of the $\mathrm{MnSO}_{4}$ solution used in the experiment. We would also like to thank Brian Schuetz and Mike Winberg for assistance in many phases of the experimental program. Thanks also are due to Wiley Davidson for permission to discuss his MCNP calculations prior to publication. We would like to express our appreciation to R. W. Moir of LLL for arranging for fabrication of an additional beryllium shell to complete the set of samples, and to K. G. Porges for locating the necessary beryllium blocks at ANL. We would also like to thank H. G. Miller, R. F. Deaton, and M. A. Avena for designing and fabricating the trolley for the neutron generator, the sample chamber, the sample-assembly cradle, and the bird cage. We thank D. A. Struttmann for writing the software to control the experiment and collect the data. The assistance of M. Bryan in the statistical analysis of the data and corrections is gratefully acknowledged. 


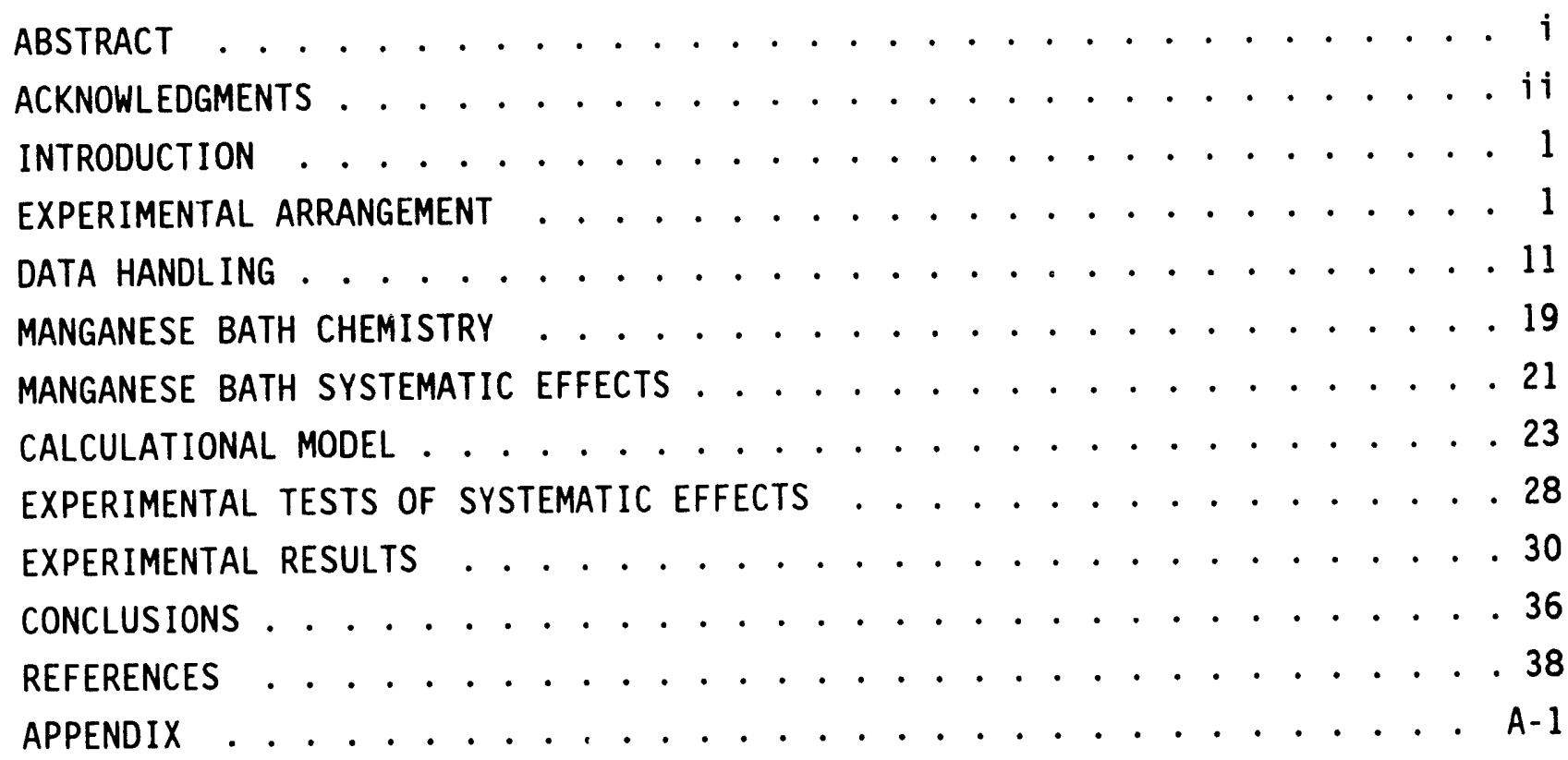

FIGURES

1. Manganese Bath and Sample Chamber . . . . . . . . . . . . . . . 3

2. Manganese Bath and Neutron Generator . . . . . . . . . . . . . . . . 4

3. Typical $\alpha$-particle spectrum from associated-particle detector . . . . 5

4. The four beryllium samples. . . . . . . . . . . . . . . . 8

5. Sample cradle with beryllium sample half assembled . . . . . . . . 11

6. Sample Be \#4 assembled on cradle with bird cage . . . . . . . . . . 12

7. Beryllium sample in place in manganese bath . . . . . . . . . . . 13

8. Mixing test of manganese bath pumps . . . . . . . . . . . . . . . . . 14

9. Growth-decay history for a typical irradiation with neutron generator 18

10. MCNP-generated diagram of the calculational model . . . . . . . . . 24

11. Apparent multiplication of neutrons in beryllium samples . . . . . 34

12. Net corrected multiplication in beryllium . . . . . . . . . . . 36 
TABLES

1. LLL BERYLLIUM SPHERICAL SHELLS .............. 6

2. BERYLLIUM EXPERIMENTAL SAMPLES ............. 7

3. COMPOSITION OF BERYLLIUM SAMPLES .............. 10

4. COMPOSITION OF THE MANGANESE BATH .............. 20

5. MANGANESE BATH CORRECTIONS: YOUNG-STEWART BERYLLIUM DATA . . . . . 26

6. MANGANESE BATH CORRECTIONS: ENDF/B-VI BERYLLIUM DATA . . . . . . 27

7. EXTRACTION OF PARASITIC ABSORPTION CORRECTION . . . . . . . 28

8. MEASURED SYSTEMATIC EFFECTS . . . . . . . . . . . . 30

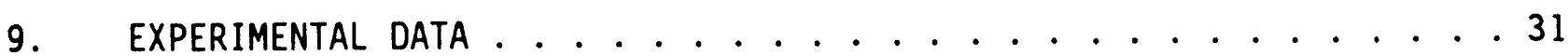

10. APPARENT MULTIPLICATION IN BULK BERYLLIUM ........... 33

11. NET CORRECTED MULTIPLICATION IN BERYLLIUM ........... 35 


\section{INTRODUCTION}

Beryllium is being considered for use as a neutron multiplier to improve the neutron economy and tritium breeding ratio of several types of fusion systems. Because beryllium has a relatively high $(n, 2 n)$ cross section with a low threshold, it should be the most effective multiplier that can be used. However, integral experiments by $\mathrm{Cloth}^{1}$, Basu et al. 2,3, and Hartley et al. ${ }^{4,5}$ indicate that the effective multiplication of $14-\mathrm{MeV}$ neutrons in bulk seryllium may be lower, by perhaps $20 \%$, than that calculated from microscopic data. On the other hand, the data of Wong et $a 1 . .^{6}$ and an old manganese bath measurement at Lawrence Livermore National Laboratory ${ }^{7}$ both indicate multiplication values as large as, or greater than, those predicted by microscopic data. The uncertainty indicated by the range of experimental values is of critical importance to the utility of beryllium as a neutron multiplier. None of these previous experiments has attained the accuracy required to resolve the discrepancy. However, $\mathrm{Chen}^{8}$ has recently reported a new measurement of the neutron multiplication in beryllium. He claims an accuracy of $2.8 \%$, and observes multiplication values $15 \%$ lower than those calculated using ENDF/B-VI data. It seemed appropriate to perform a new measurement using the manganese bath, employing techniques that have been refined in many respects since the Livermore experiment ${ }^{7}$ was performed.

\section{EXPERIMENTAL ARRANGEMENT}

\section{Principle of the Measurement}

The manganese bath is the preferred method for the measurement of the absolute value of neutron source strengths. It has a history of success in the measurement of neutron multiplicities for ${ }^{252} \mathrm{Cf}$ and the fissile nucle ${ }^{9}$, as well as for the measurement of emission rates of neutron sources of various energy spectra. ${ }^{10}$ It has the advantages that it is a $4 \pi$ detector, and its response is very uniform as a function of both angle and energy of the neutrons. The effect of these advantages is that the manganese bath may detect neutrons that may be missed by other detection methods. 
In the manganese bath method a neutron source is placed at the center of a totally-absorbing aqueous solution of $\mathrm{MnSO}_{4}$. The capture of neutrons by $\mathrm{Mn}$ produces a ${ }^{56} \mathrm{Mn}$ activity proportional to the emission rate of the source. As applied to the measurement of the multiplication of 14-MeV neutrons in bulk beryllium, the neutron source is a tritium target placed at the end of the drift tube of a small deuteron accelerator. Surrounding the source is a sample chamber. When the sample chamber is empty, the neutrons go directly to the surrounding $\mathrm{MnSO}_{4}$ solution, and produce a ${ }^{56} \mathrm{Mn}$ activity proportional to the neutron emission rate. When the chamber contains a beryllium sample, the neutrons first enter the beryllium and multiply through the $(n, 2 n)$ process. Neutrons escaping from the beryllium enter the bath and produce a ${ }^{56} \mathrm{Mn}$ activity proportional to the neutron emission rate multiplied by the effective value of the multiplication in bulk beryllium. The ratio of the activities with and without the sample present is proportional to the multiplication value. Irradiations are monitored by and normalized to the counting rate of the associated $\alpha$-particle detector.

\section{Manqanese Bath}

The manganese bath assembled for the beryllium multiplication experiment is shown in Figure 1. It utilizes a polyethylene tank, basically cylindrical in shape, but with an ellipsoidal domed top. The inside diameter of the tank is approximately $181.9 \mathrm{~cm}$ and the inside maximum height is $188.9 \mathrm{~cm}$. The wall thickness is $1.27 \mathrm{~cm}$. Shown with the tank is the sample chamber, which is an aluminum cylinder of inside diameter and height $60.96 \mathrm{~cm}$, mounted on aluminum legs and a supporting base of stainless steel. The structure is assembled inside the tank.

The $\mathrm{MnSO}_{4}$ solution is circulated by two Crane Series 800 Dynapumps. One of these is the mixing pump. It continuously pumps solution from the lower part of the bath to a pair of diffusing nozzles near the top of the bath, at a rate of about 2.5 liters per second. The second pump is the flow pump. It continuously draws solution from the lower part of the bath, at a position opposite that of the mi:ing pump, and delivers it to the detectors, then returns it to the top of the bath. The flow rate to each detector is about 0.27 liters 


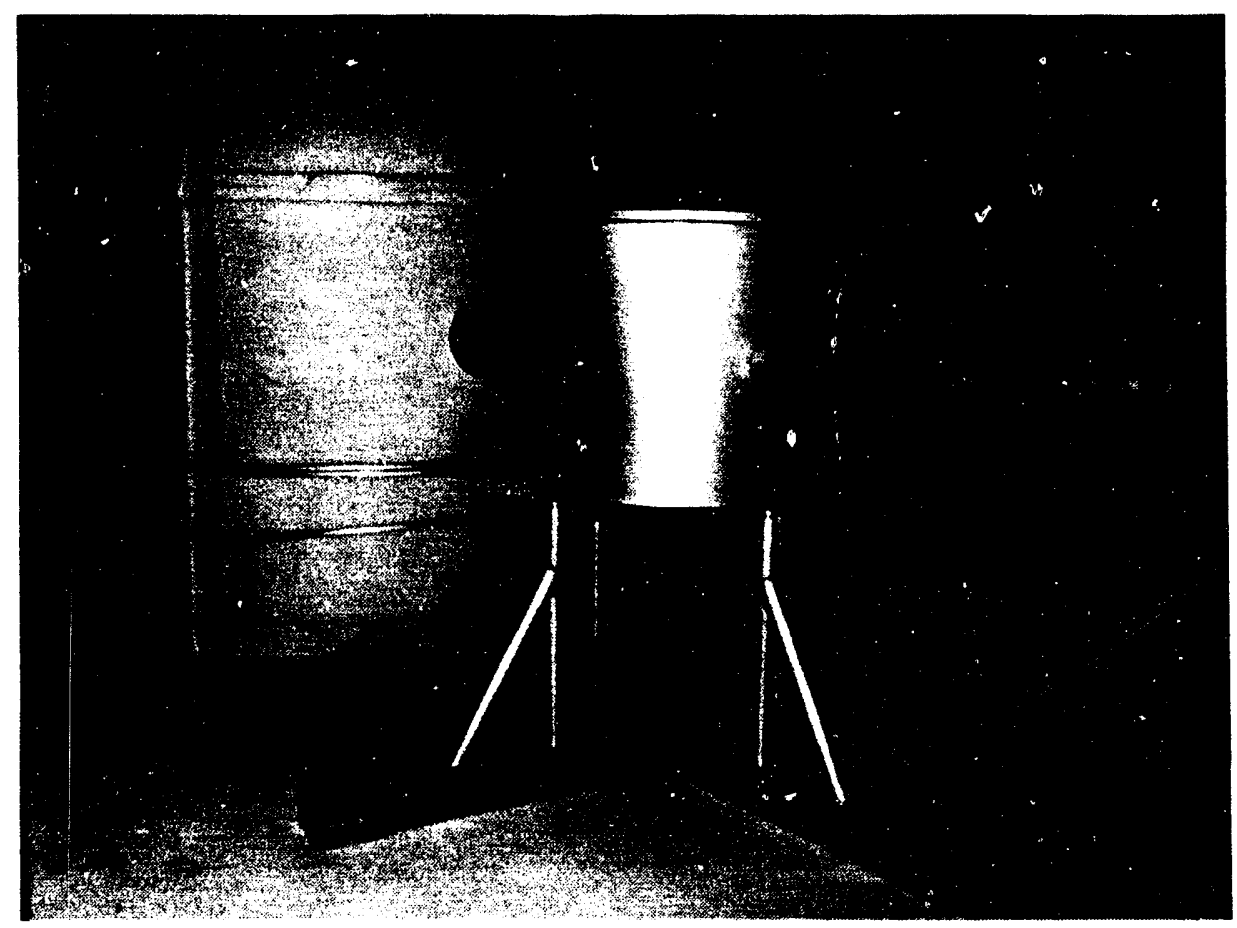

Figure 1. Mangariese Bath and Sample Chamber

per second. The detectors are a pair of $7.6 \mathrm{~cm} \times 7.6 \mathrm{~cm} \mathrm{NaI}(T 1)$ scintillation counters. Counting is done continuously, during both the growth and decay phases of the irradiation.

\section{Neutron Generator}

Figure 2 shows the neutron generator installed at the manganese bath. The banding now seen on the tank minimizes bulging as the tank is filled, and preserves the alignment of the neutron generator. The generator is mounted upon a trolley that allows the neutron source to be placed at the center of the bath for irradiations or withdrawn for change of samples. The drift tube and target chamber are based upon the low-mass design developed at Livermore for their pulsed-sphere measurements ${ }^{11}$. An associated-particle detector is mounted at $174^{\circ}$ to the incident beam. It is located in the undersiung portion of the cone seen at the end of the drift tube in Figure 2 . 


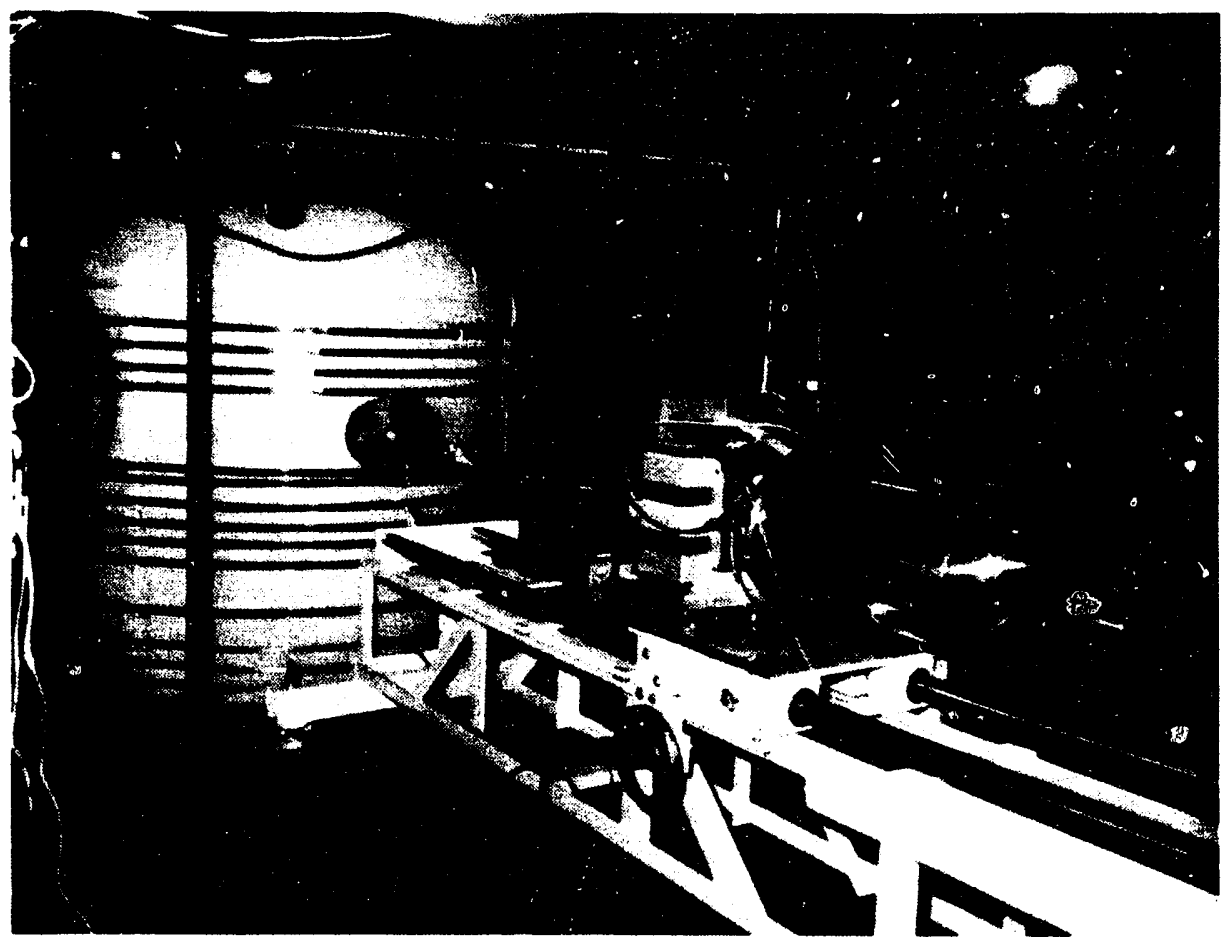

Figure 2. Manganese Bath and Neutron Generator

The most stable mode of operation of the neutron generator is to maintain the machine potential at a constant $150 \mathrm{kV}$. The machine has a Penning ion source and no beam analyzer. Therefore the beam arriving on target is a mixture of atomic and molecular ions. A typical spectrum of associated alpha particles is shown in Figure 3 . The principal peak represents alpha particles from $(d, t)$ collisions involving the molecular beam. Analysis of the pulse-height spectrum from the $\alpha$-detector indicated that approximately $97 \%$ of the $(d, t)$ ions in the beam were molecular, with the remainder being atomic. The deuteron beam energy is therefore $97 \% 75 \mathrm{keV}$ and $3 \% 150 \mathrm{keV}$. Typically the generator produces approximately $10^{8} 14-\mathrm{MeV}$ neutrons per second.

A single-channel analyzer accepts pulses under the alpha peak for monitoring of the neutron yield of the source. The background under the alpha peak is approximately $0.75 \%$ of the foreground. Since the data are ultimately used in the form of ratios of activities, the small background is of negligible consequence. 


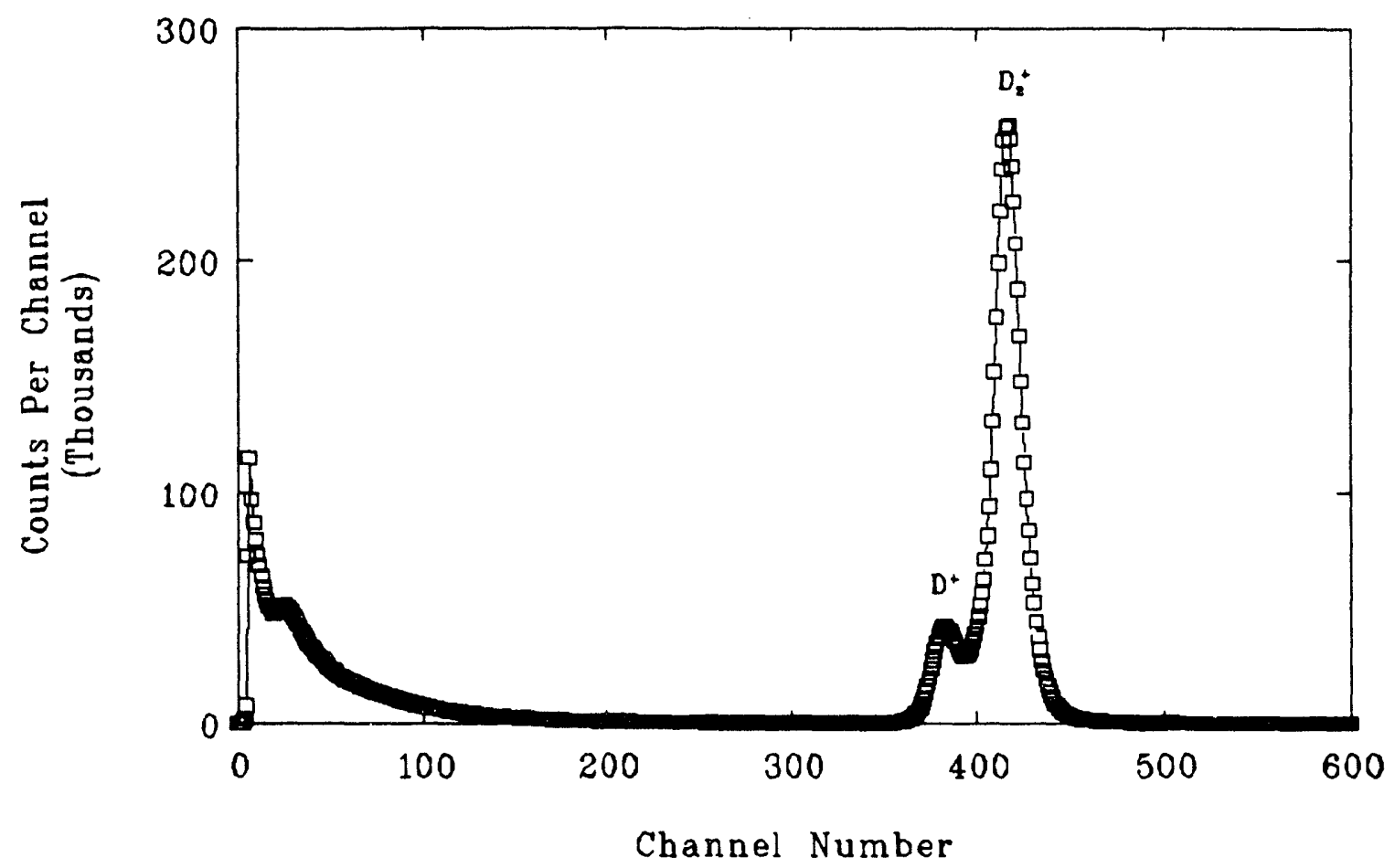

Figure 3. Typical a-particle spectrum from associated-particle detector.

\section{Beryllium Samples}

The beryllium samples used in this experiment were obtained on loan from Lawrence Livermore Laboratory (LLL). Table 1 describes the physical dimensions of the samples. They are the same set of beryllium spherical shells used in the Hartley ${ }^{4,5}$, and Wong ${ }^{6}$ measurements, with one exception. The experiments of Hartley et al. and Wong et al. were handicapped by having a void in the position represented by the shell designated $L-8$ in Table 1 . The original beryllium shells fabricated for this part of the set have been missing for many years. Through the efforts of Ralph Moir of LLL and Karl Porges of ANL a replacement shell for this position has finally been fabricated. A set of beryllium blocks, $15.2 \mathrm{~cm} \times 15.2 \mathrm{~cm} \times 7.6 \mathrm{~cm}$, was provided by ANL. The LLL shop cemented these blocks together, using epoxy cement, to form a beryllium monolith from which piece L-8 was machined. This piece contains a quantity of epoxy cement 
TABLE 1. LLL BERYLLIUM HEMISPHERICAL SHELLS

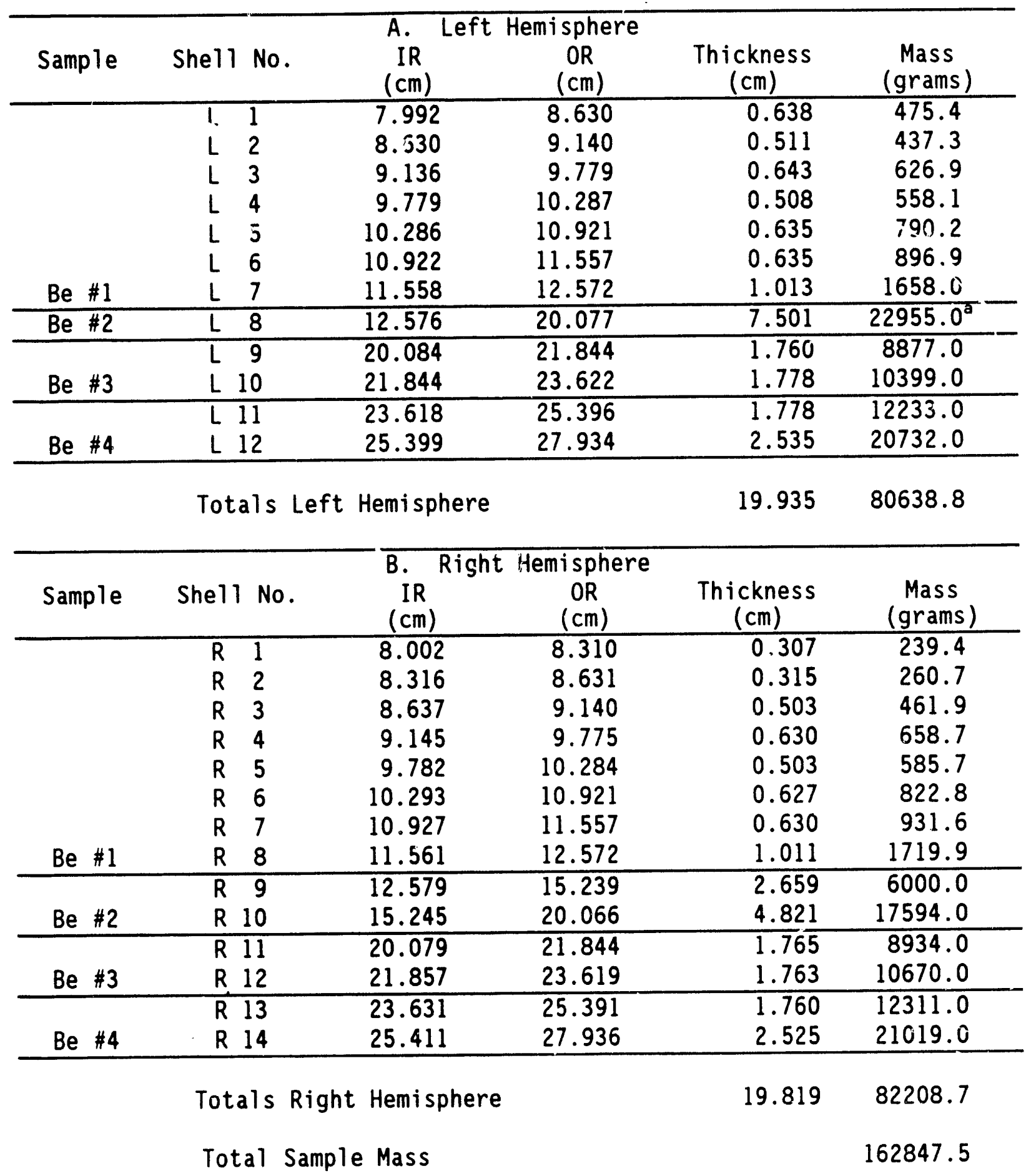

- Shel1 L 8 mass includes approximately 84.72 g D-85 cement. 
calculated to be 84.72 grams. The epoxy is included in the list of impurities in the sample. The presence of the L-8 shell greatly improves the experiment. Without it we would have been required either to leave out the shells on the right-hand side opposite the void, or to fill the void with an aiuminum can containing BeO. Either of these steps would have posed severe problems in the performance and iuterpretation of the experiment.

Table 1 shows that there are a total of 12 shells in the hemisphere through which the drift tube of the neutron generator enters, and 14 shells in the opposite hemisphere. The horizontal lines demark the grouping into the four experimental samples used. The left-hand shells are lighter than the right-hand shells because of they contain the entrance holes for the drift tube of the neutron generator. The assembled dimensions of the four experimental samples are described in Table 2. In keeping with the variations in dimension among the

TABLE 2. BERYLLIUM EXPERIMENTAL SAMPLES

\begin{tabular}{|c|c|c|c|c|c|}
\hline $\begin{array}{c}\text { Sample } \\
\text { No. }\end{array}$ & $\begin{array}{l}\text { IR } \\
(\mathrm{cm})\end{array}$ & $\begin{array}{l}\text { OR } \\
(\mathrm{cm})\end{array}$ & $\begin{array}{c}\text { Thickness } \\
(\mathrm{cm})\end{array}$ & $\begin{array}{l}\text { Mass } \\
(\mathrm{kg})\end{array}$ & $\begin{array}{c}\text { Fraction } \\
\text { Solid }\end{array}$ \\
\hline $\begin{array}{l}\mathrm{Be} \# 1 \\
\mathrm{Be} \# 2 \\
\mathrm{Be} \# 3 \\
\mathrm{Be} \# 4\end{array}$ & $\begin{array}{l}8.0 \\
8.0 \\
8.0 \\
8.0\end{array}$ & $\begin{array}{l}12.6 \\
20.1 \\
23.6 \\
27.9\end{array}$ & $\begin{array}{r}4.6 \\
12.1 \\
15.6 \\
19.9\end{array}$ & $\begin{array}{r}11.12 \\
57.67 \\
96.55 \\
162.85\end{array}$ & $\begin{array}{l}0.9791 \\
0.9850 \\
0.9880 \\
0.9905\end{array}$ \\
\hline
\end{tabular}

shells the dimensions are rounded off to one decimal place and the mass to two decimal places. Table 2 also lists the "Fraction Solid" for the four samples. This is the ratio of the mass of the actual sample to the mass that would be present without the entrance hole for the drift tube. The values were calculated by assuming that the left-hand shells would have the same mass as the right-hand shells if the holes were not present. The calculation neglects the effect of several small holes cut in the samples for alignment pins and foil irradiation positions. The four assembled experimental samples are pictured in Figure 4. Each sample sits on its own stand, which is of aluminum with holes punched to 


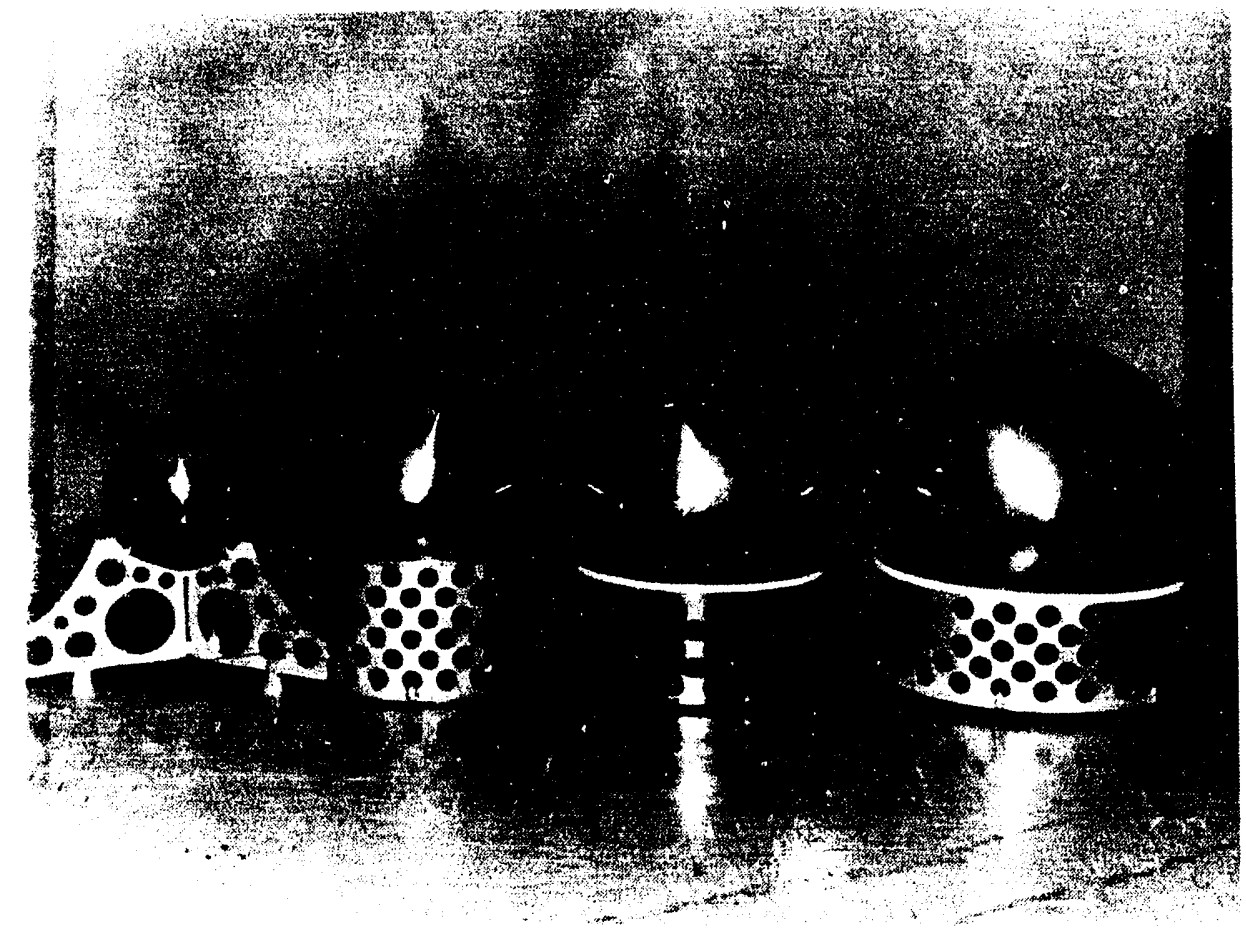

Figure 4. The four beryllium samples. From left to right: Be \#l, $\mathrm{Be} \# 2$, Be \#3, and $\mathrm{Be} \# 4$.

decrease the neutron absorption of the structure.

Because the LLL samples were fabricated many years ago, no record of a chemical analysis of these specific pieces could be located. When piece L- 8 was fabricated, however, an analysis was made of one of the scrap pieces. The results of this analysis appear in Table 3 . We assume that the composition of the older samples was similar to that of L-8. Therefore the Table 3 data were used for all of the beryllium samples used in this experiment.

The mechanical problems associated with placing a $162.8-\mathrm{kg}$ beryllium sample in proper alignment at the center of the manganese bath and removing it proved challenging. It is important to keep the structural materials as light as possible to minimize neutron absorption, while providing adequate support for the 
heavy samples. The largest beryllium sample consists of twenty-six hemispherical shel1s. Entrance holes for the neutron generator drift tube are at an angle of $45^{\circ}$ to the equator for the inner shells, and $90^{\circ}$ for the outer shells. The problem is to assemble these shells into an array whose final orientation has the equator of the outer shells $3^{\circ}$ off of the vertical, with the equator of the inner shells at $45^{\circ}$ to the rest of the sample. The $3^{\circ}$ offset is to allow for the underslung position of the $\alpha$-particle detector. After assembly the whole sample must be lifted above the manganese bath and lowered into the sample chamber in such a manner that the holes are properly aligned to allow entrance of the drift tube of the neutron generator. The mechanism devised for handling these tasks is illustrated in Figures 5 through 7 . The apparatus was adapted from a tilting cradle for 208-liter drums. An alignment spindle, which just fits the entrance holes of the beryllium shells, is mounted on the cradle. The beryllium sample is assembled, shell by shell, upon the cradle, with the entrance holes fitted down over the spindle. Figure 5 shows the cradle with the large sample half assembled. When the assembly is complete, the sample holder, which we have named the bird cage, is clamped down over the beryllium. The bird cage consists of a cylindrical aluminum base, upon which the sample will sit in the sample chamber of the manganese bath, and a close-fitting spider arrangement, whose four arms fit down around the beryllium and hook into slots in the base. Figure 6 shows sample Be \#4 in the bird cage, assembled on the cradle. The tilting feature of the cradle has been utilized, and the sample is rotated to a vertical position. The sample is then released from the cradle and lifted by a forklift to a drum dolly on the working platform above the manganese bath. A slow-speed half-ton hoist lifts the sample from the dolly and lowers it into the sample chamber of the bath. Figure 7 shows the sample safely installed in the sample chamber. 
TABLE 3. COMPOSITION OF BERYLLIUM SAMPLES ${ }^{\circ}$

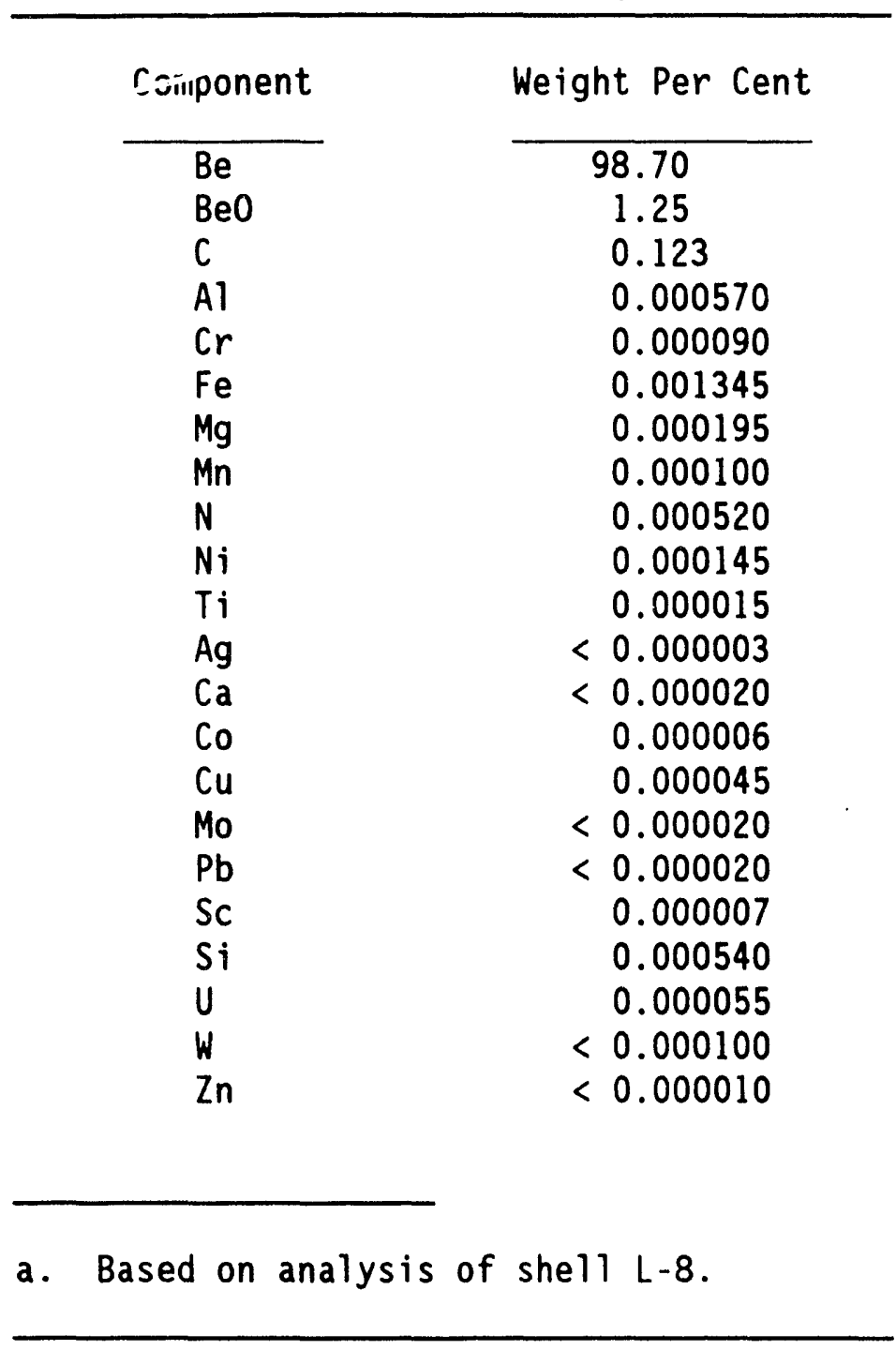




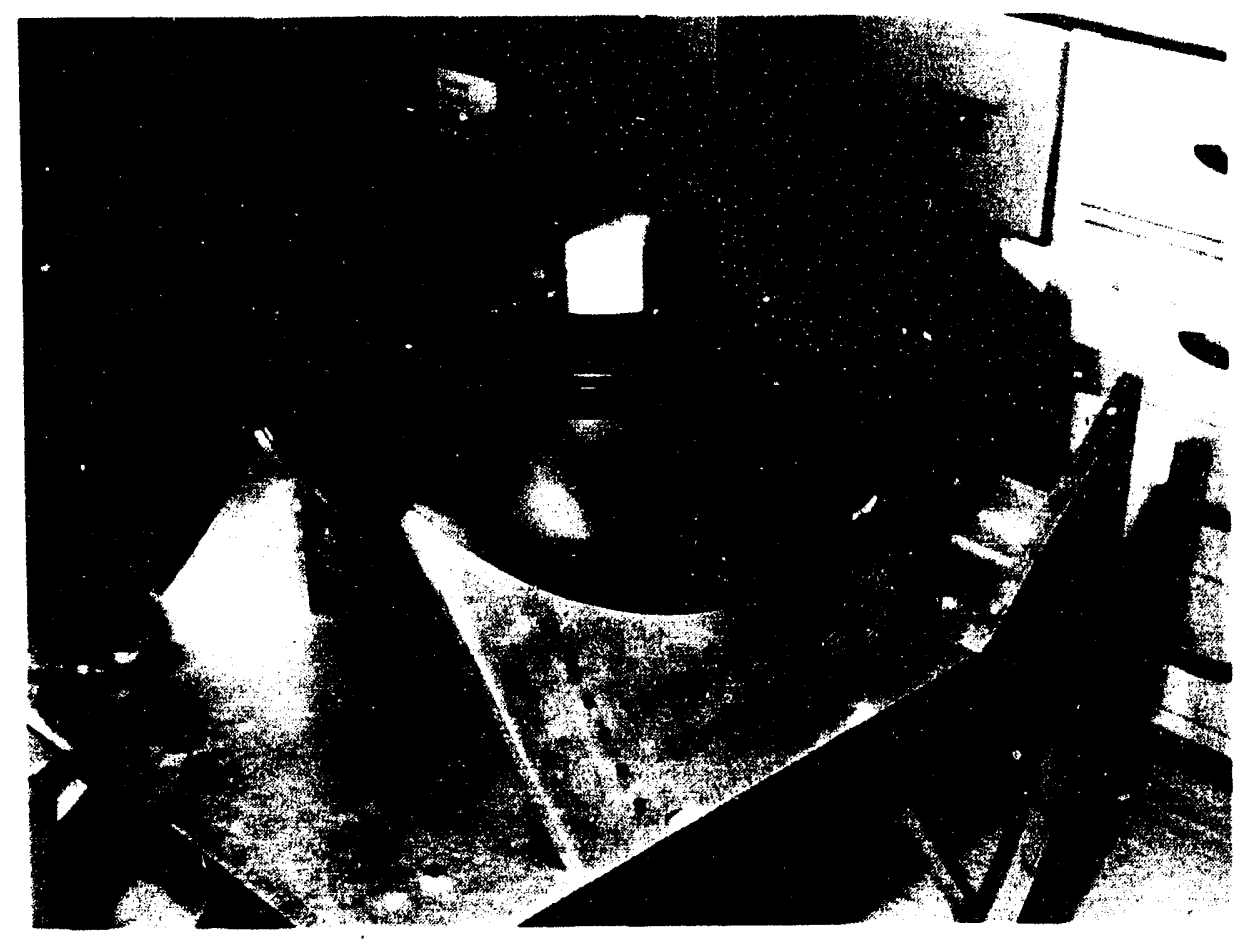

Figure 5. Sample Cradle with Beryllium Sample Half Assembled.

DATA HANDLING

Data from two manganese bath detectors, the associated $\alpha$-particle detector, a current integrator, a paraffin-moderated neutron detector, and a $5 \mathrm{~cm} \times 5 \mathrm{~cm}$ NE-213 fast-neutron scintillator are routinely collected in Camac scalers. The latter two detectors monitored the neutron leakage from the bath. The temperatures indicated by two thermocouples mounted on the drift tube of the neutron generator are also recorded. An IBM PC/AT computer controls the collection of data. The MANSAT ${ }^{9}$ program performs the data analysis.

MANSAT is based upon the concept of manganese flow counting developed at the University of Michigan by D. M. Gilliam and others ${ }^{12}$. The total ${ }^{56} \mathrm{Mn}$ activity in the system is considered to consist of two components. The bulk of the activity has been present for at least the homogenization time, $\tau$, and is counted 


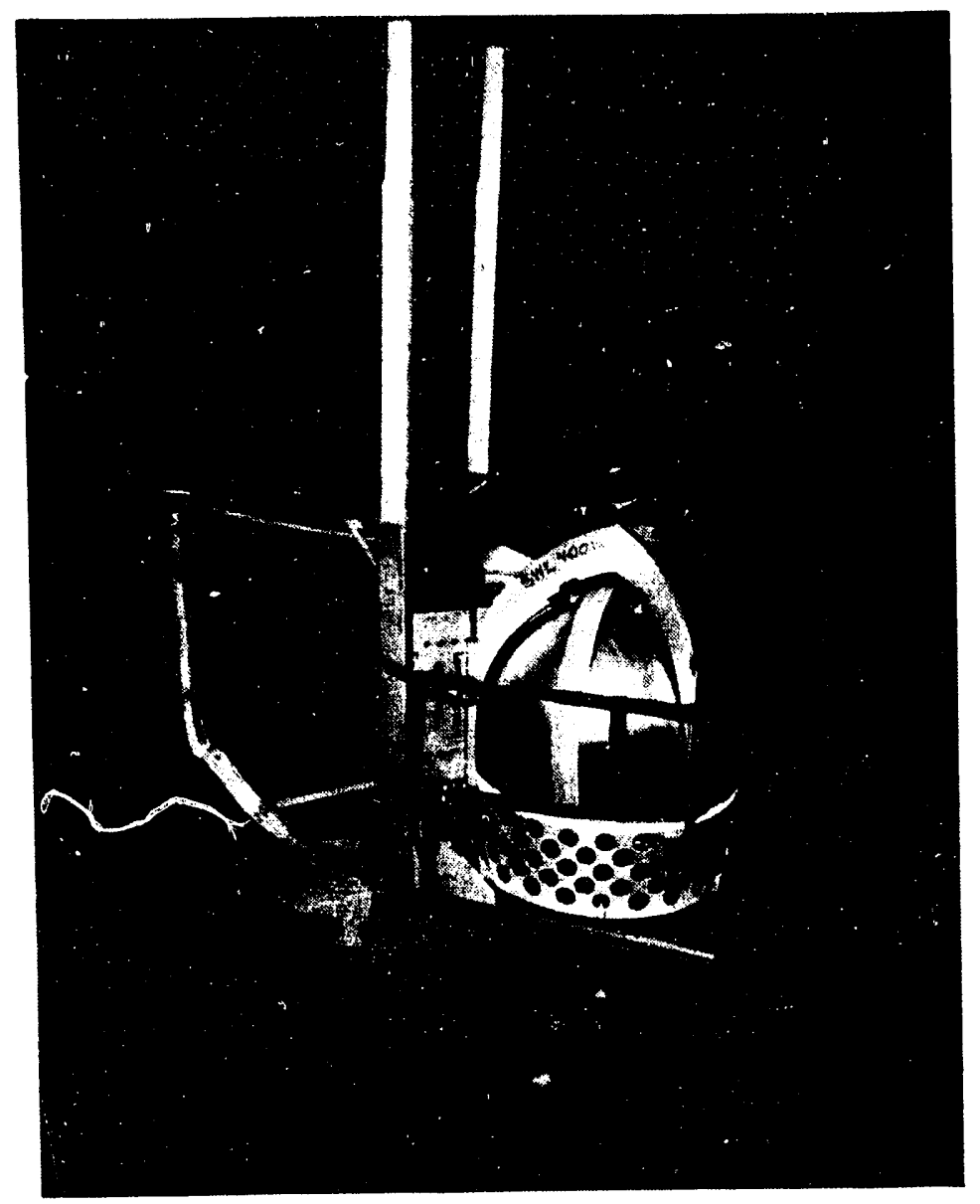

Figure 6. Sample Be \#4 Assembled on Cradle with Bird Cage.

with the an efficiency $\varepsilon$, which is the efficiency for detecting the calibrated ${ }^{56} \mathrm{Mn}$ activity mixed into the bath at calibration time. The second component is activity that has been too recently produced to allow full homogenization. It is counted with an effective efficiency of $\epsilon(1-\delta)$, where $\delta$ represents the fractional efficiency loss for the activity that is not homogenized. The two mixing parameters, $\tau$ and $\delta$, are not independent of each other. An approximate value for $\tau$ is adopted, and $\delta$ is adjusted to achieve consistency in the calculations of saturated activity. If the value of $\delta$ is too low, the calculated saturated activity values are relatively low at the beginning of the irradiation (the growth phase), gradually increasing to a constant value as the irradiation continues, and leveling off at a value below the activities calculated from the 


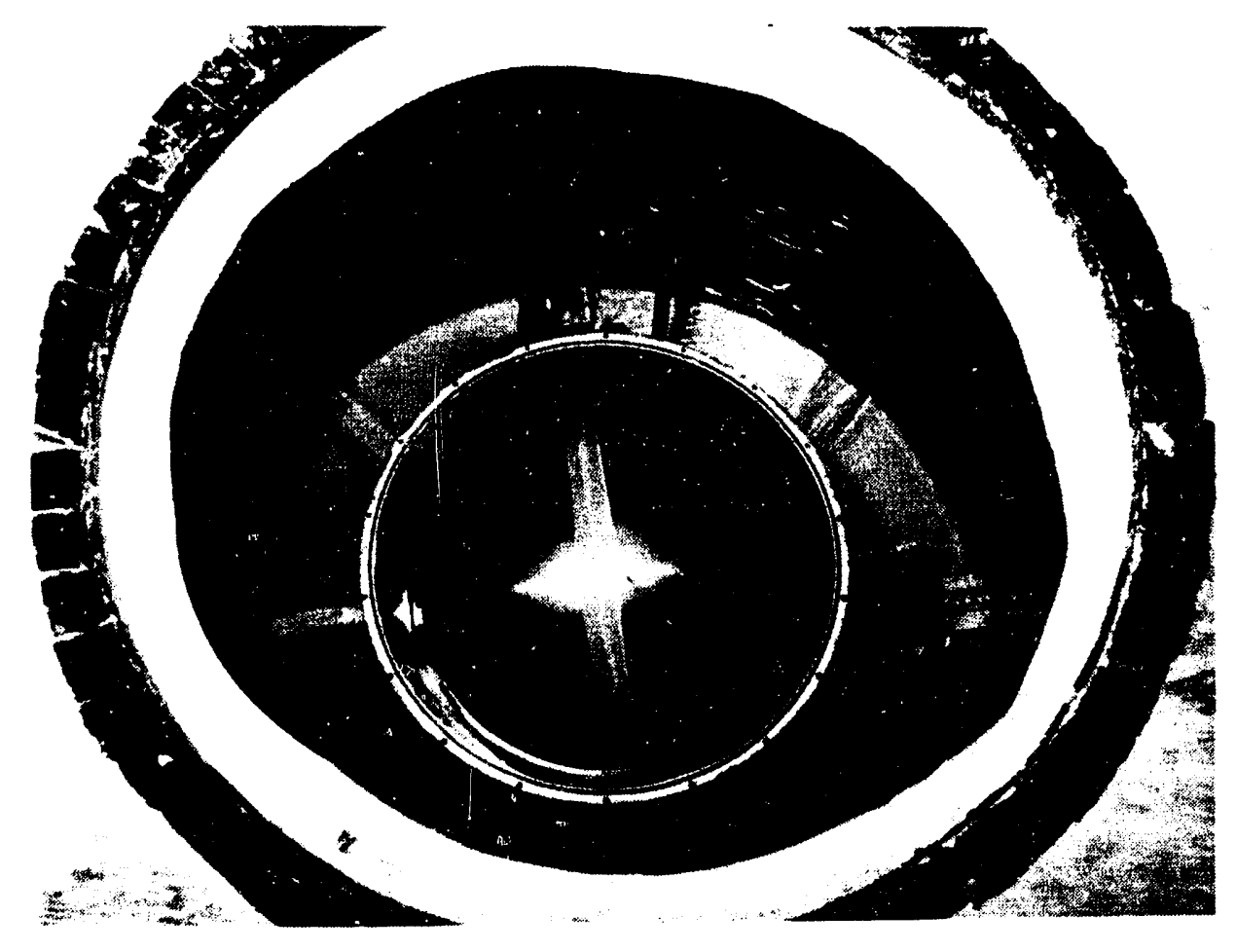

Figure 7. Beryllium Sample in Place in Manganese Bath

decay phase of the experiment. If the value of $\delta$ is too high, the calculated saturated activity values begin high, decreasirig with time and leveling off at a value higher than the values from the decay phase. MANSAT includes a search routine to vary $\delta$ until the slope of the calculated saturated activity curve is less than $10^{-7}$. When the slope is thus minimized, the growth data are found to agree closely with the decay data.

A test of the homogenization time was conducted in conjunction with a neutron leakage measurement. With the pumps off, the bath was irradiated for two hours, during which time the detectors measured background activity. Then the two pumps were turned on simultaneously, and the activity measured in 30 -second intervals. The rise in activity is represented in Figure 8 . The solution is well homogenized within the 600-second homogenization time adopted for all manganese bath data reduction. 


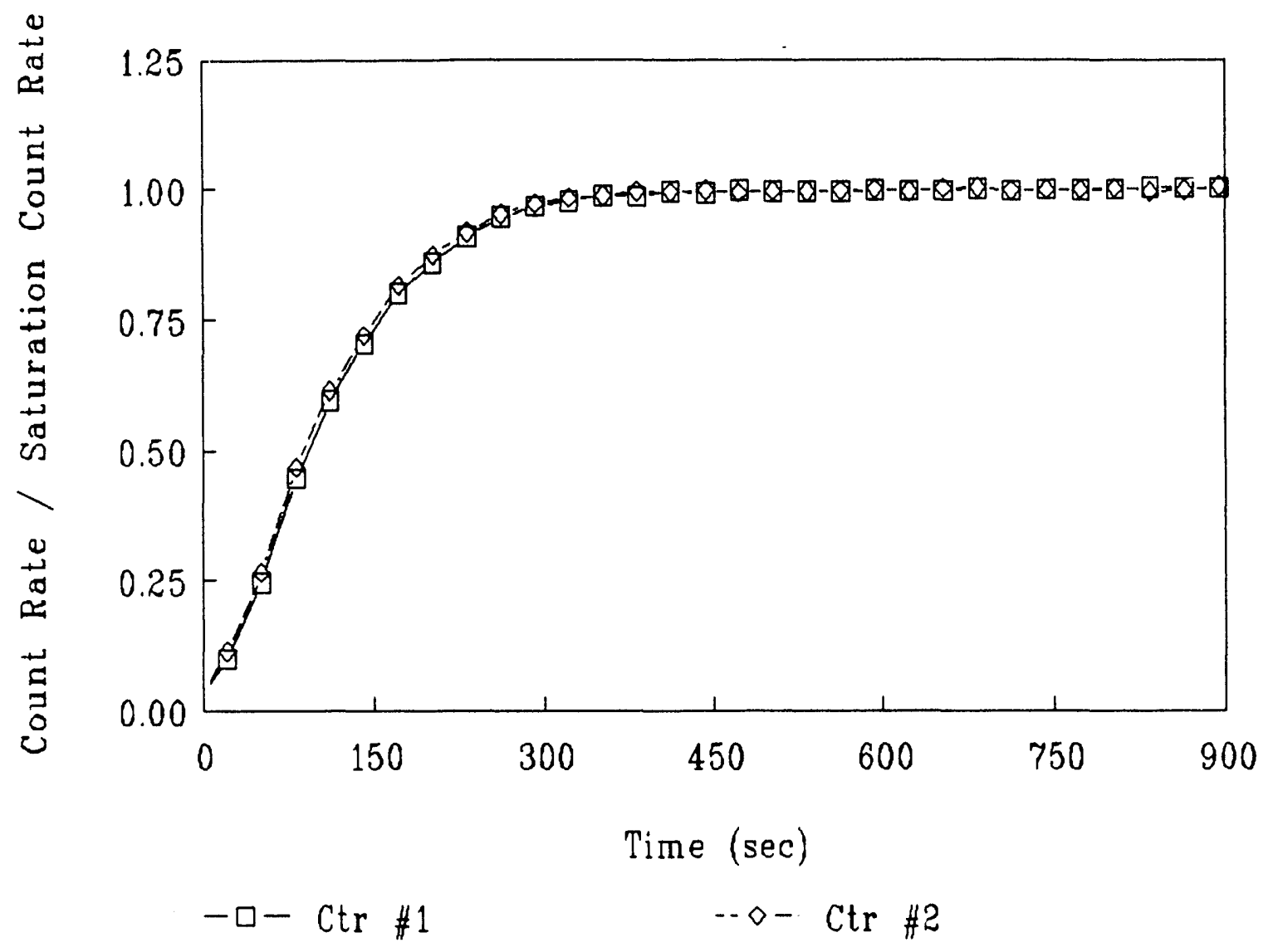

Figure 8. Mixing Test of Manganese Bath Pumps.

\section{Manganese Bath Response Equations: ${ }^{252} \mathrm{Cf}$ Source}

For a ${ }^{252} \mathrm{Cf}$ source the saturated activity, as indicated by the data from the nth counting period during the irradiation (growth phase), is given by $A_{s g n}=C_{n} A_{1 n} /\left(A_{2 n}-\delta A_{3 n}\right)$,

with

$$
\begin{aligned}
& A_{1 n}=\exp \left(\lambda_{s} t_{n}\right)\left(\lambda_{m}-\lambda_{s}\right) / \lambda_{m} . \\
& A_{3 n}=\left\{1-\exp \left[\left(\lambda_{s}-\lambda_{m}\right) \tau\right]\right\}\left[1-\exp \left(-\lambda_{s} t_{c}\right)\right] / \lambda_{s} .
\end{aligned}
$$




$$
A_{2 n}=\exp \left[\left(\lambda_{s}-\lambda_{m}\right) t_{n}\right]\left[\exp \left(-\lambda_{m} t_{c}\right)-1\right] / \lambda_{m}+\left[1-\exp \left(\lambda_{s} t_{c}\right)\right] / \lambda_{s},
$$

Following the removal of the ${ }^{252} \mathrm{Cf}$ source the saturated activity as indicated by the nth decay-phase count is given by

$$
A_{s d n}=\frac{C_{n}\left(\lambda_{m}-\lambda_{s}\right) \exp \left[\lambda_{m}\left(t_{n}-t_{I}\right)\right]}{\left[1-\exp \left(-\lambda_{m} t_{c}\right)\right]\left[\exp \left(-\lambda_{s} t_{I}\right)-\exp \left(-\lambda_{m} t_{I}\right)\right]} .
$$

In Equations 1 to $5 C_{n}$ represents the total number of counts, corrected for dead-time losses, background, and residual activity, observed during the counting period $t_{c}$, which began at a time $t_{n}$ after insertion of the source into the bath. The duration of the irradiation is given by $t_{1}$. The decay constants of manganese and the source are represented by $\lambda_{\mathrm{m}}$ and $\lambda_{\mathrm{s}}$, respectively. The two mixing parameters, $\tau$ and $\delta$, are described above.

The decay factors for ${ }^{252} \mathrm{Cf}$ contained in Equations 1 to 5 account for the effects of decay of the source during the irradiation. A further decay correction is applied to deduce the source strength at an earlier reference date, following determination of the weighted average of the saturated activity values.

\section{Manganese Bath Response Equations: Neutron Generator}

The response equations in the case of a ${ }^{252} \mathrm{Cf}$ source are relatively simple because the neutron source strength changes only slowly and predictably over the period of the irradiation. The neutron generator is less predictable. The source strength increases as the machine warms up and decreases as the target becomes depleted of its tritium. In addition there may be fluctuations in the performance of the ion source. These variations affect the ${ }^{56} \mathrm{Mn}$ counting in two ways. In the first place, variation of the neutron source strength requires that each count be normalized to the counting rate observed in the associated $\alpha$ particle detector. In the second place, consideration must be given to the fact 
that each ${ }^{56} \mathrm{Mn}$ data point contains contributions from activations produced during the whole prior history of the irradiation. To account for these effects, we developed a "neutron generator" version of MANSAT. It assumes that the source strength is constant over each counting period, the counting period being chosen to make this approximately so. The irradiation period is assumed to consist of a series of short irradiation periods, with the nth count containing decayweighted contributions from all of the previous irradiation period. The homogenization time is presumed to extend back into the $n$-1 th counting period. Under these assumptions the manganese bath response takes the following form.

$$
W_{s g n}=C_{n} /\left(G_{1 n}-\delta G_{2 n}\right),
$$

with

$$
\begin{aligned}
& G_{1 n}=D_{1} \sum_{k=1}^{n-1} \rho_{\alpha k} \exp \left[-(n-k-1) \lambda t_{c}\right]+D_{2} \rho_{\alpha n}, \\
& G_{2 n}=D_{3} \rho_{\alpha(n-2)}+D_{1} \rho_{\alpha(n-1)}+D_{2} \rho_{\alpha n} .
\end{aligned}
$$

The D's are combinations of decay parameters:

$$
\begin{aligned}
& D_{1}=\left[1-\exp \left(-\lambda_{m} t_{c}\right)\right]^{2} / \lambda_{m} \\
& D_{2}=t_{c}-\left[1-\exp \left(-\lambda_{m} t_{c}\right)\right] / \lambda_{m}, \\
& D_{3}=\exp \left(-\lambda_{m} t_{c}\right)\left[1-\exp \left(-\lambda_{m} t_{c}\right)\right] / \lambda_{m}-t_{c} \exp \left(-\lambda_{m} \tau\right) .
\end{aligned}
$$

$W_{\text {sgn }}$ is the saturation value of the ${ }^{56} \mathrm{Mn}$ activity, as indicated by the $n$th count observed during the growth period of the irradiation, normalized to the 
decay-weighted associated particle counting rate. $\rho_{\alpha n}$ is the average counting rate of the associated particle detector observed during the nth counting period. The irradiation continues for $\underline{N}$ cuunting periods, after which counting continues during the decay phase of the run. During the decay phase the $\alpha$-normalized saturation activity is given by

$$
W_{\mathrm{sdn}}=\frac{C_{n} \lambda_{m} \exp \left[\lambda_{m}\left(t_{n}-t_{1}\right)\right]}{\left[1-\exp \left(-\lambda_{m} t_{c}\right)\right]^{2} \sum_{k=1}^{N} \rho_{\alpha k} \exp \left[-(N-k) \lambda_{m} t_{c}\right]} .
$$

As with the neutron source version of the program, the mixing parameters $\tau$ and $\delta$ are determined by assuming a value for $\tau$ and adjusting $\delta$ to force the growth curve to be flat. The mixing parameters for the neutron source and neutron generator versions of MANSAT are very nearly equal, as they depend principally upon the mechanical characteristics of the manganese bath. There appears to be a very small dependence upon the neutron spectrum, and the value of $\delta$ is slightly smaller for the $14-\mathrm{MeV}$ neutrons than for ${ }^{252} \mathrm{Cf}$ neutrons. In the present experiment we used a value of $\tau=600 \mathrm{sec}$. The fitted values of $\delta$ are about 0.19 for $14-\mathrm{MeV}$ neutrons and 0.21 for ${ }^{252} \mathrm{Cf}$ neutrons.

Because both the neutron generator and ${ }^{252} \mathrm{Cf}$ source produce excellent statistical precision in the decay phase of the experiment, we use only the decay data. However, the growth data were also routinely calculated and examined for indications of any irregularities in the irradiation. Saturation values from the entire growth-decay cycle were plotted for examination. A typical plot is shown in Figure 9. Data from the growth phase are plotted as $\underline{1}^{\prime} s$, and the decay data are indicated by $\underline{2}^{\prime} s$. The facts that the history is very flat, and that the growth and decay data merge smoothly, indicate that the mixing parameters have been properly determined and that there are no serious experimental problems with this irradiation.

The statistically-weighted average of the $W_{\text {sdn }}$ values is $W_{s}{ }^{i}$ for an irradiation using beryllium sample $i$, and $W_{s}{ }^{\circ}$ for an open beam irradiation. The 


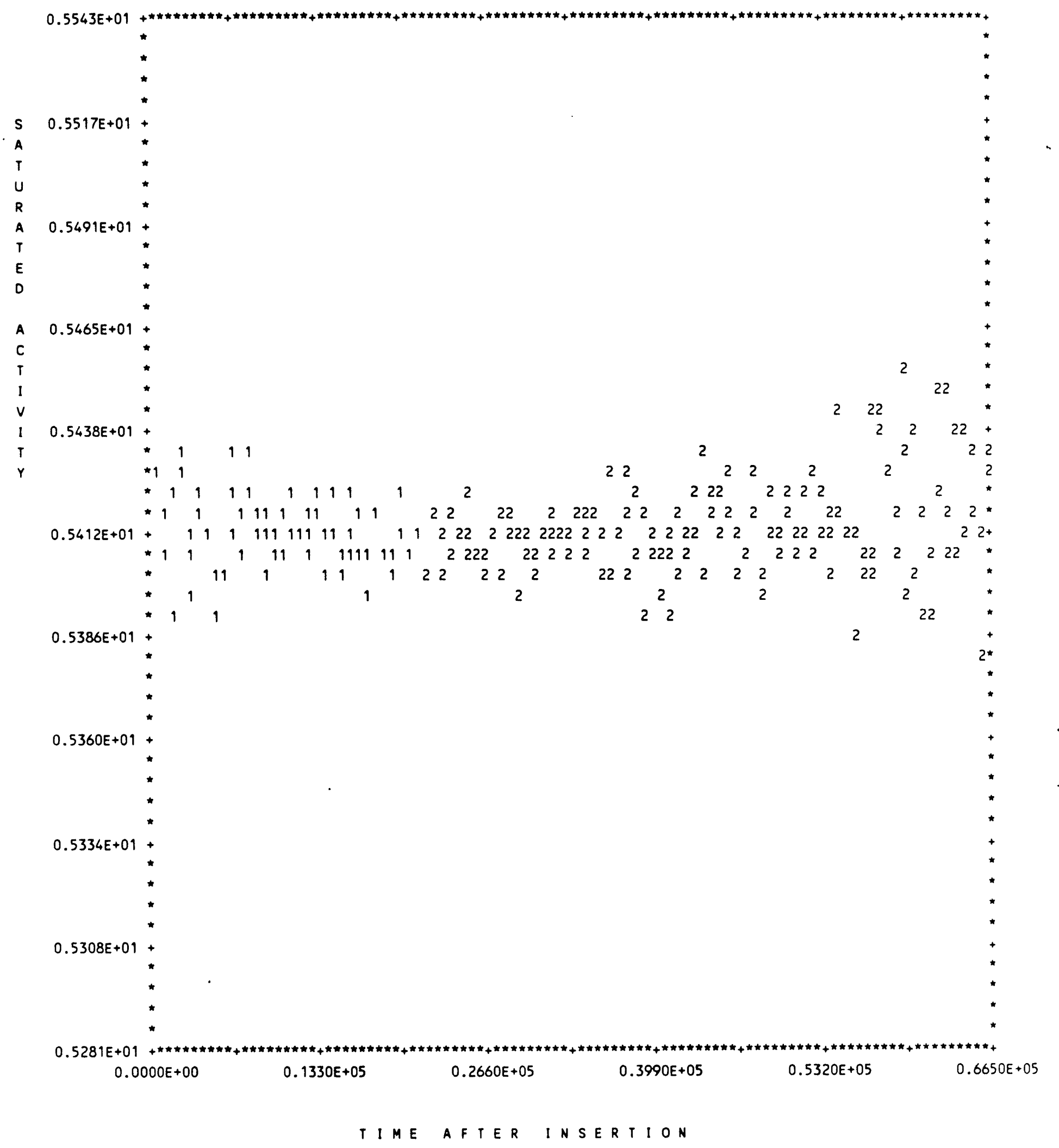

Figure 9. Growth-Decay History for a Typical Irradiation with the Neutron Generator. 
ratio $W_{S}{ }^{i} / W_{S}{ }^{\circ}$ is the apparent multiplication $M_{A}{ }^{i}$ for the beryllium sample. $M_{A}{ }^{i}$ is the quantity that can be compared directly with calculation to test the effectiveness of cross section data and calculational methods. For the true multiplication of the sample the effects of the manganese bath upon the measurement must be considered.

\section{MANGANESE BATH CHEMISTRY}

In order to set up the MCNP model properly, and to be sure that there are no substantial amounts of absorbers in the $\mathrm{MnSO}_{4}$ solution that would disturb the neutron economy of the system, it is necessary that the solution be well characterized. There is a certain amount of evaporation with time, and it is necessary to have a record of the consequent change in concentration to make appropriate corrections in the experimental data. For these reasons we measured the solution concentration routinely. Concentration measurements were made both gravimetrically (by evaporating a sample of solution to dryness and weighing the residue) and titrametrically (by titration with EDTA). Both methods are used, because earlier work ${ }^{9}$ showed that the level of impurities in the solution is indicated by the difference between the two measurements. For a solution of high purity the titrametric result gives the concentration of manganese, while the gravimetric method yields the total quantity of solids in the solution. Concentrations for the solution sample collected 2 June 1989 are shown in Part I of Table 4. Because the MNCP model of the experiment requires information concerning the number density of all component nuclei, the solution density is also measured. The density of the 2 June 1989 sample is shown in Table 4 along with the other concentration data. 
TABLE 4. COMPOSITION OF THE MANGANESE BATH

I. Manganese Bath Concentration on 2 June 1989

$\frac{\begin{array}{c}\text { Gravimetric } \\ (\mathrm{g} / \mathrm{Kg})\end{array}}{212.71}$

$\begin{gathered}\text { Titrametric } \\ (\mathrm{g} / \mathrm{kg})\end{gathered}$
211.953

$\begin{array}{ll}\text { Ratio G/T } & \begin{array}{c}\text { Density } \\ (\mathrm{g} / \mathrm{ml})\end{array} \\ 1.00357 & 1.23354\end{array}$

II. Impurities in the Manganese Bath

Element

At. Wt. (barns)

Chem. Form Concentration $(\mu \mathrm{g} / \mathrm{ml})$

$\underset{\left(\mathrm{cm}^{-1}\right)}{\Sigma}$

\begin{tabular}{c} 
\\
\hline $\mathrm{Li}$ \\
$\mathrm{B}$ \\
$\mathrm{Cd}$ \\
$\mathrm{Fe}$ \\
$\mathrm{Mg}$ \\
$\mathrm{Al}$ \\
$\mathrm{Na}$
\end{tabular}

\begin{tabular}{ccc} 
& & \\
\cline { 1 - 1 } 6.941 & & 71 \\
10.811 & & 765 \\
112.41 & & 2450 \\
55.847 & & 2.56 \\
24.305 & & 0.063 \\
26.9815 & & 0.233 \\
22.9898 & & 0.53
\end{tabular}

$\mathrm{Li} \mathrm{SO}_{4}$
$\mathrm{H}_{3} \mathrm{BO}_{3}$
$\mathrm{CdSO}_{4}$
$\mathrm{Fe}_{2} \mathrm{SO}_{4}$
$\mathrm{MgSO}_{4}$
$\mathrm{Al}_{2}\left(\mathrm{SO}_{4}\right)_{3}$
$\mathrm{Na}_{2} \mathrm{SO}_{4}$

\begin{tabular}{ccc} 
Element & & Sulfate \\
\cline { 1 - 1 } 0.045 & & 0.358 \\
0.054 & & 0.309 \\
0.093 & & 0.172 \\
4.447 & & 15.92 \\
6.084 & 30.11 \\
18.908 & 119.7 \\
79 & & 487.7
\end{tabular}

$2.772 \mathrm{E}-07$

$2.301 \mathrm{E}-06$

$1.221 \mathrm{E}-06$

$1.228 \mathrm{E}-07$

$9.496 \mathrm{E}-09$

$9.833 \mathrm{E}-08$

$1.097 \mathrm{E}-06$

Absorption associated with oxygen and sulfur in impurities

$1.780 \mathrm{E}-06$

Total absorption in impurities

$6.906 \mathrm{E}-06$

Ratio $\Sigma_{\text {Imp }} / \Sigma_{M n}$

0.000494

The concentration history showed that throughout the course of the experiment the manganese concentration increased at an average rate of $0.036 \%$ per day. The experimental data were corrected for this concentration change.

To complete the characterization of the solution we have determined the level of various impurities in the bath. The impurities are summarized in Part II of Table 4. With the exception of boron, the impurity leveis were measured by Inductively Coupled Plasma (ICP) analysis. For boron we use the results of 
a colorometric measurement. The right-hand column shows the macroscopic thermal neutron absorption cross section represented by each impurity element. To these values must be added the contributions from the sulfur and oxygen in the impurity sulfate molecule (or borate, in the case of boron). The total impurity macroscopic absorption cross section is approximately $0.05 \%$ of that of the manganese in the bath.

The 1 ist of impurities in Table 4 represenis a somewhat abbreviated list, the list having been shortened somewhat to simplify the MCNP setup. A few other impurities, of negligible absorption, have been neglected.

\section{MANGANESE BATH SYSTEMATIC EFFECTS}

With the sample chamber empty, the saturated ${ }^{56} \mathrm{Mn}$ activity of the bath is given by the relation

$$
W_{s}^{\circ}=\frac{4 \pi}{\omega_{\alpha}} R_{\alpha} \in f^{\circ}\left(1-L^{\circ}-D^{\circ}-P^{0}-S^{\circ}+N_{s}\right) \text {. }
$$

With a beryllium sample in the chamber, the $\alpha$-normalized saturated activity becomes

$$
W_{\mathrm{s}}^{i}=M_{\text {pure }}^{i} \frac{4 \pi}{\omega_{\alpha}} R_{\alpha} \in f^{i}\left[1+\frac{N_{\mathrm{s}}^{i}+N_{\mathrm{Im}}^{i}+N_{\mathrm{Be}}^{\prime i}-A_{\mathrm{Be}}^{\prime i}-A_{\mathrm{Im}}^{i}-L^{i}-D^{i}-S^{i}-P^{i}}{1+N_{B e}^{i}-A_{B e}^{i}}\right] .
$$

In Equations 2 and 3 the superscript 0 refers to the value of the particular quantity when the sample chamber is empty, and the superscript i refers to the value when the sample chamber contains beryllium sample $i$. $\omega_{\alpha}$ is the solid angle subtended by the $\alpha$ detector, and $R_{\alpha}$ is the anisotropy correction factor required to relate the alpha counting rate to the total neutron yield. The efficiency factor $e$ is the efficiency of the $\mathrm{NaI}(\mathrm{Tl})$ detectors for counting ${ }^{56} \mathrm{Mn}$ activity anywhere in the bath system. $M_{\text {pure }}$ is the multiplication in just the beryllium of the sample. The factors $N$ account for small multiplication contributions due to $(n, 2 n)$ reactions on the structural materials, including the manganese of the bath $\left(N_{s}\right)$, impurities in the beryllium $\left(N_{I m}\right)$, and neutrons returning from the bath to the beryllium $\left(\mathrm{N}^{\prime}{ }_{B e}\right)$. The factors $A$ represent the 
absorption of primary neutrons in the beryllium $\left(A_{B e}{ }^{i}\right)$, the absorption of returned neutrons in the beryllium $\left(A^{\prime}{ }_{B e}{ }^{i}\right)$, and absorption of neutrons by the impurities in the beryllium $\left(A_{I m}{ }^{i}\right)$. The factors $f$ represent the fraction of neutrons absorbed in manganese in the Maxwellian part of the spectrum in the bath, expressed by the relation

$$
f=\frac{N_{M n} \sigma_{M n}(1+G r S)}{N_{M n} \sigma_{M n}(1+G r S)+N_{H} \sigma_{H}+N_{O} \sigma_{O}+N_{S} \sigma_{S}+\sum N_{I} \sigma_{I}}
$$

In Eq. (15) the $N^{\prime} s$ are the number densities, and $\sigma^{\prime} \mathrm{s}$ are the $2200 \mathrm{~m} / \mathrm{sec}$ cross sections of manganese, hydrogen, oxygen, sulfur, and whatever impurities are in the bath. The term $(1+G r s)$ is a correction, using the Westcott formalism, for the absorption in the manganese resonances, principally the one at $336 \mathrm{eV}$. The Westcott $g$ factor is unity. The $G$ represents a correction for self-shielding in the manganese resonances, and $\underline{r}$ represents Westcott's $\underline{r}$ factor, which is essentially the resonance integral. The resonance correction depends upon the spectrum, which in our case varies with the amount of beryllium between the source and the bath. The resonance correction is not large, and the ratio $f^{0} / f^{i}$ varies very little from unity. $L, D, S$, and $P$ are corrections for leakage, duct streaming, absorption in structural materials, and absorption in high-energy charged particle reactions, respectively. Most of the corrections are spectrum-dependent. With no beryllium sample present, the manganese bath sees the pristine 14-MeV spectrum, which becomes thermalized in the bath. When beryllium is present, it acts as a moderator as well as a multiplier, and the manganese bath sees a partially moderated spectrum. The systematic effects have different values for each sample thickness.

Equations (13) and (14) can be combined to deduce the true multiplication value for the beryllium sample: 


$$
M_{\text {puI }}^{i}=\frac{W_{s}^{i} f^{0}}{W_{s}^{0} f^{i}} \frac{1-L^{0}-D^{0}-S^{0}-P^{0}+N_{s}^{0}}{\left[1+\frac{N_{s}^{i}+N_{I m}^{i}+N_{B \theta}^{i}-A_{B \theta}^{i}-A_{I m}^{i}-L^{i}-D^{i}-S^{i}-P^{i}}{1+N_{B e}^{i}-A_{B e}^{i}}\right]}
$$

Equation 16 shows an impressive array of corrections to be evaluated. Fortunately most of the effects are small in size. For fission, $(\alpha, n)$, and $(\gamma, n)$ sources the manganese bath systematic effects have been widely studied by both experimental and calculational techniques, and corrections can be made to a high level of confidence. For $14-\mathrm{MeV}$ neutrons some of the corrections are much 1 arger than for lower-energy sources, and their uncertainties are also larger. Values of the corrections were extracted from detailed edits of the Monte Carlo calculation of the experiment.

\section{CALCULATIONAL MODEL}

The experiment was modeled by Dr. Wiley Davidson of Los Alamos ${ }^{13}$ for calculations using the Monte Carlo code MCNP. An extremely detailed model of the experiment was constructed. Figure 10 is a diagram of the model, as generated by the MCNP program. Cross sections used were from ENDF/B-V, with the exception of beryllium, for which two different cross-section sets were used. The first calculations were made using the evaluation by Young and Stewart (YS), ${ }^{14}$ because the ENDF/B-VI data for beryllium were not yet available to MCNP. The purpose of Young and Stewart in performing their evaluation was to cast an approximation to the LLL evaluation into the ENDF/B-V format. It was not accepted for ENDF/B-V, but is available from ENDF/A, as well as the European Fusion File. The LLL evaluation, with some further modifications, became the ENDF/B-VI data file. Recently this program supported the necessary conversion of MCNP to utilize the ENDF/B-VI beryllium cross section data. A description of the conversion work appears in the Appendix.

A large variety of MCNP tallies were kept to allow extraction of the values of individual corrections as well as the value of the apparent 


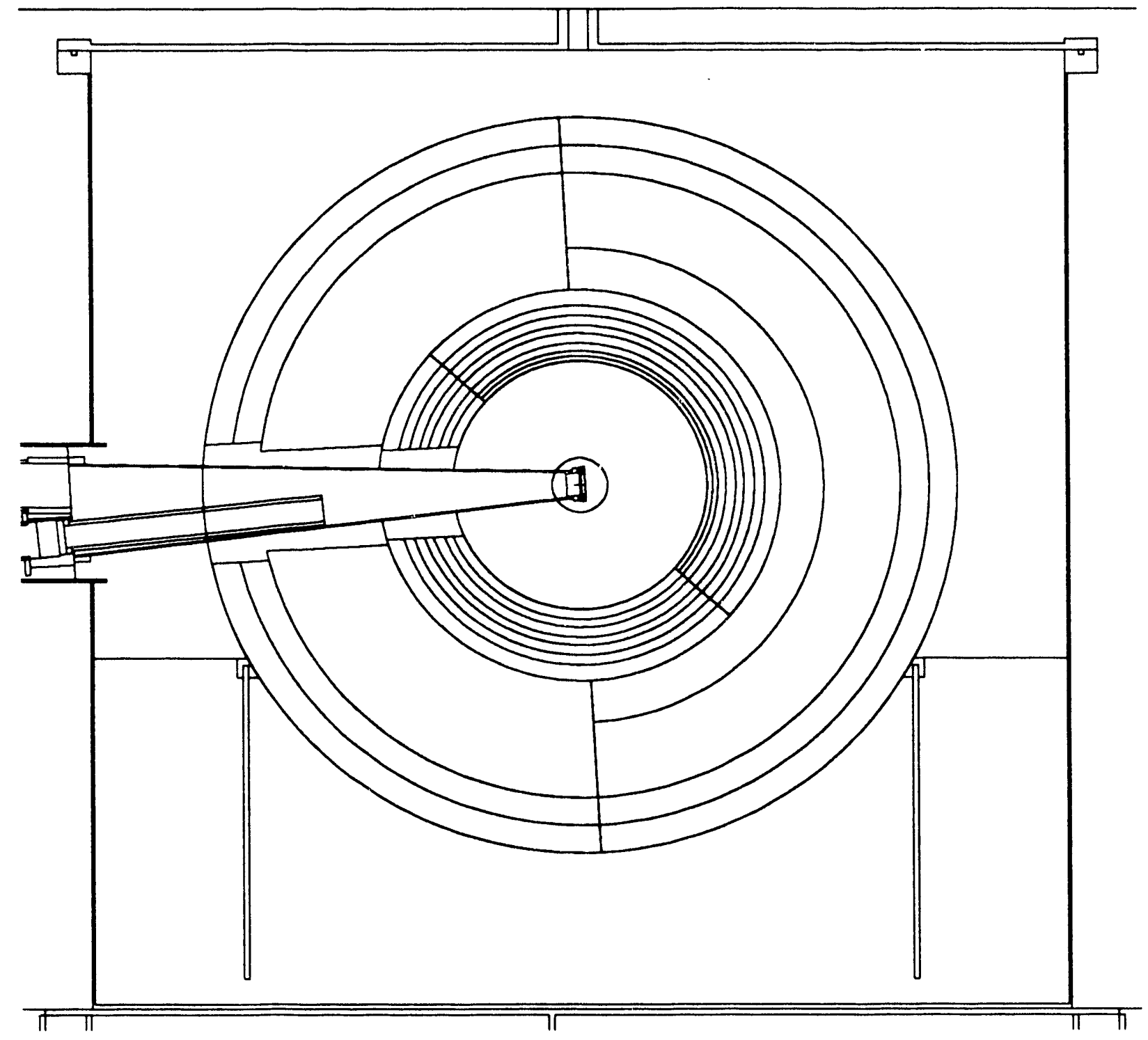

Figure 10. MCNP-generated diagram of the calculational model. Be\#3 is represented.

multiplication $M_{A}$. The values of the systematic effects for the open beam and the individual beryllium samples are listed in Table 5 , for calculations using the YS beryllium data, and Table 6, for calculations using the ENDF/B-VI beryllium data. The manganese bath corrections are relatively insensitive to the particular beryllium data set used. The differences between the two evaluations is registered in the $(n, 2 n)$ and absorption events recorded for 
each. The uncertainties shown are the MCNP statistical uncertainties, except for the parasitic absorption correction $P$; which carries a $20 \%$ uncertainty because of the uncertainties in the cross sections.

When a neutron returned from the bath to the beryllium sample, it was flagged by MCNP. The indirect multiplication effect was evaluated from multiplications due to the flagged neutrons. The flagged tallies also showed non-multiplying absorptions of returned neutrons. Absorptions in beryllium include not only $(n, \gamma)$ events but also $(n, \alpha)$ and $(n, t)$ reactions, which are non-negligible. In Table 5 the effects labeled $N^{\prime}{ }_{B e}$ and $A^{\prime}{ }_{B e}$ represent the effects of $(n, 2 n)$ and absorption reactions, respectively, due to neutrons returning from the bath to the berylliur Multiplication due to the returned neutrons is very low, because neutrons $u_{1}$ ergoing enough scattering events to return them to the beryllium will most prodably lose enough energy to take them below the $(n, 2 n)$ threshold. 


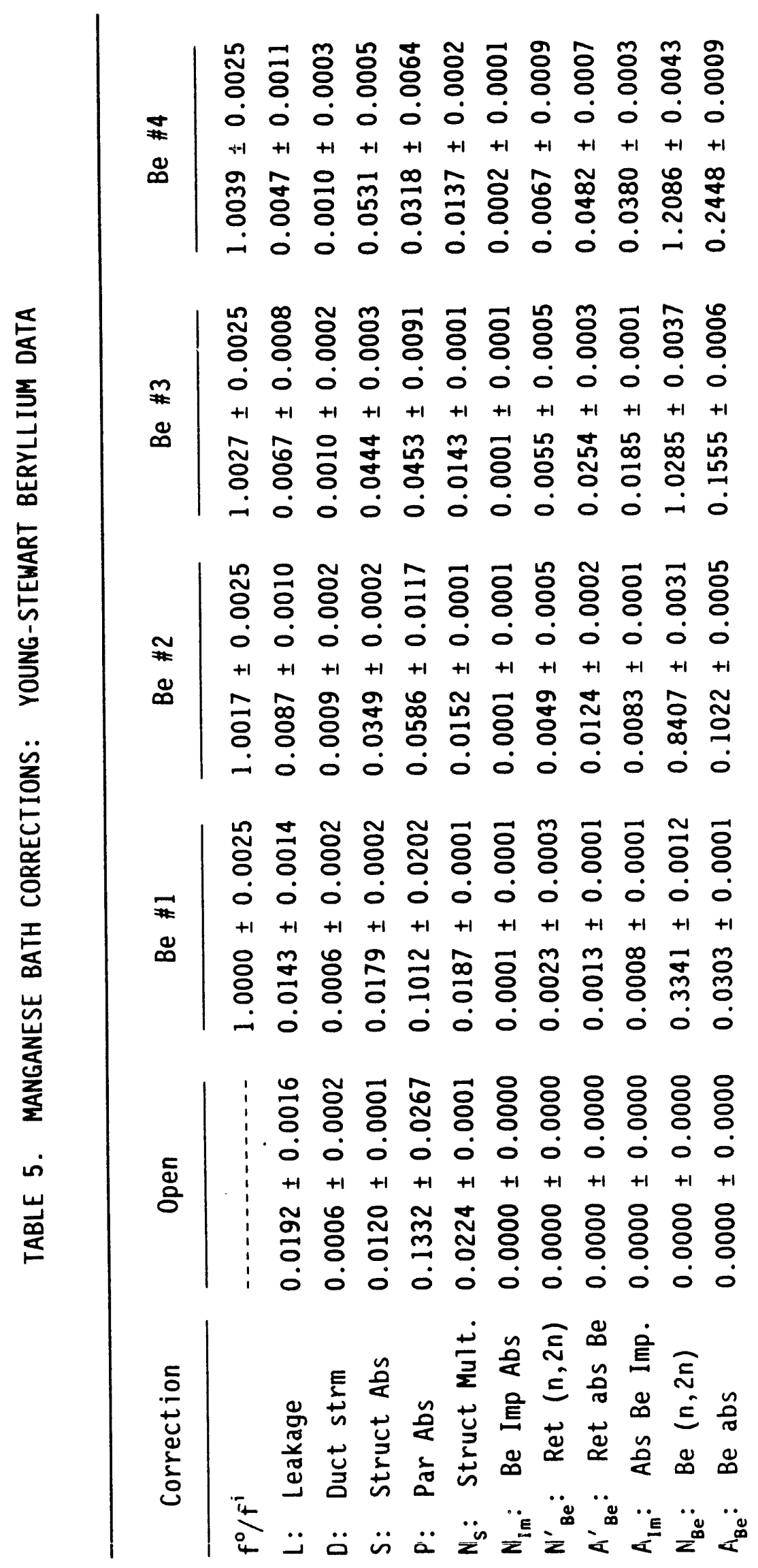




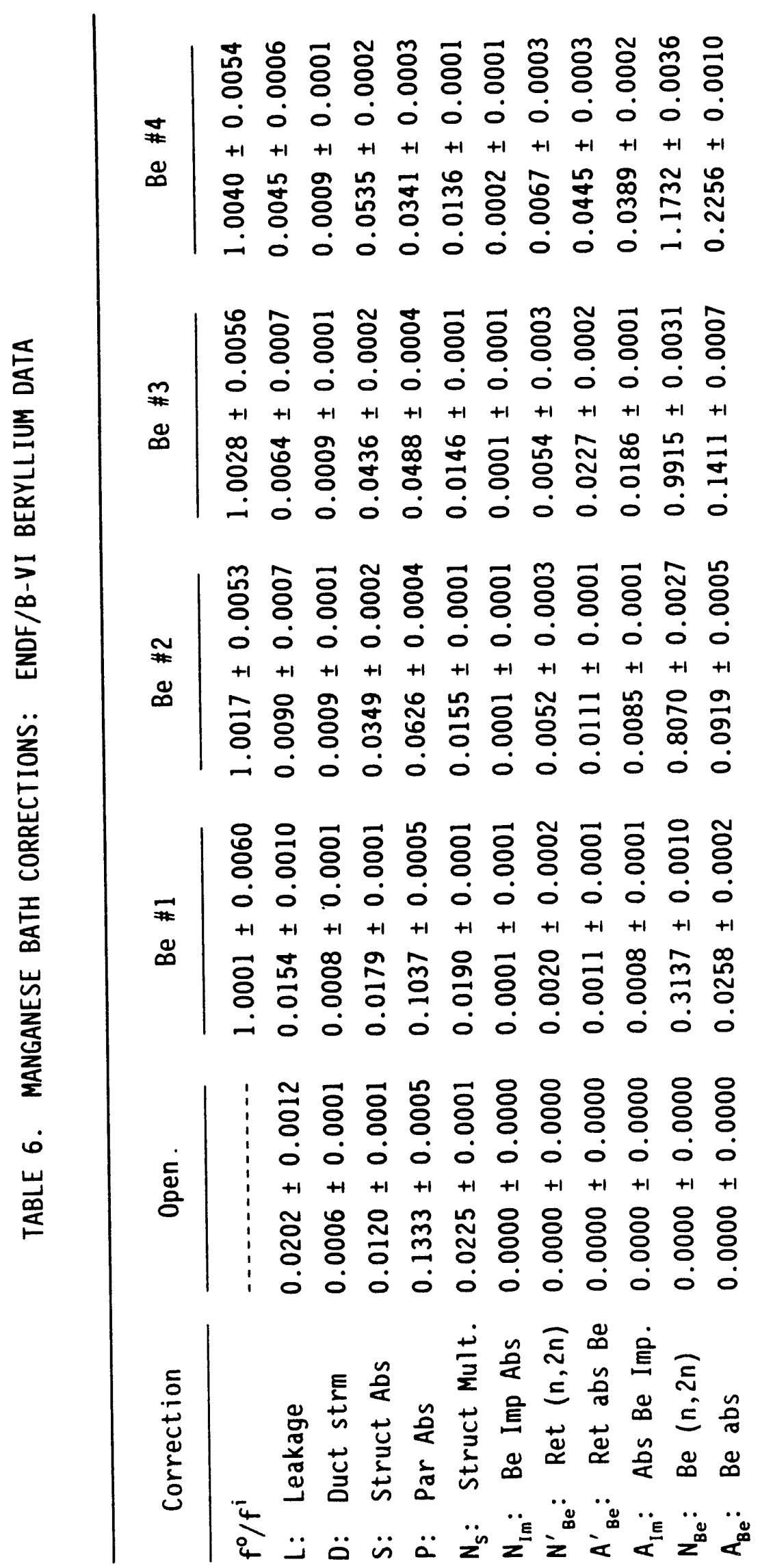




\section{EXPERIMENTAL TESTS OF SYSTEMATIC EFFECTS}

It was possible to obtain experimental values for three of the corrections calculated by MCNP. These were the parasitic absorption, leakage, and structural absorption for the open beam, and the structural absorption for samples $\mathrm{Be} \# 2$ and $\mathrm{Be} \# 4$.

The correction for parasitic absorption is the largest and most troublesome of the corrections. Estimates of its magnitude have ranged as high as $25 \%{ }^{15}$ The presence of the associated particle detector makes it possible to obtain an exporimental check upon the value of this correction, which normally can only be calculated. The efficiencies of the manganese bath counters were measured by adding a calibrated aliquot of ${ }^{56} \mathrm{Mn}$ activity to the bath. The $\alpha$-detector subtends a fractional solid angle $\left(\omega_{\alpha} / 4 \pi\right)$ of $1.5816 \times 10^{-5}$. The anisotropy factor $R_{\alpha}$ was calculated using the computer program RALPHA. ${ }^{16}$ The remaining correction factors contained in Equation (13) are small and have small uncertainties. The values of those parameters not listed in Tables 5 and 6 are shown in Table 7 . The resultant value for the

TABLE 7. EXTRACTION OF PARASITIC ABSORPTION CORRECTION

\begin{tabular}{|c|c|c|}
\hline Parameter & Value, ctr \#1 & Value, ctr \#2 \\
\hline$W_{s}^{0}$ & $5.42667 \pm 0.00036$ & $5.34808 \pm 0.00098$ \\
\hline$\omega_{\alpha} / 4 \pi$ & $(1.5816 \pm 0.0035) E-05$ & $(1.5816 \pm 0.0035) E-05$ \\
\hline$e$ & $(2.2867 \pm 0.0077) E-04$ & $(2.2538 \pm 0.0076) E-04$ \\
\hline $\mathrm{R}_{\alpha}$ & $1.146 \pm 0.018$ & $1.146 \pm 0.018$ \\
\hline$f^{\circ}$ & $0.39224 \pm 0.00098$ & $0.39224 \pm 0.00098$ \\
\hline$P$ & $0.136 \pm 0.014$ & $0.136 \pm 0.014$ \\
\hline
\end{tabular}


parasitic absorption correction deduced from this approach is 0.136 . The value calculated by MCNP is 0.133 . The latter value is higher than the value (0.123) previously reported, ${ }^{17}$ because the final MCNP calculations included absorption by the $(n, d),(n, t)$, and $\left(n,{ }^{3} \mathrm{He}\right)$ reactions in the bath. For $14-\mathrm{MeV}$ neutrons these reactions become significant factors, whereas for lower energy neutrons only the $(n, p)$ and $(n, \alpha)$ cross sections are normally considered.

The recent ENDF/B-VI evaluation for oxygen ${ }^{18}$ raised the ${ }^{16} 0(n, \alpha){ }^{13} \mathrm{C}$ cross sections by approximately $25 \%$ above the ENDF/B-V values. As our experimental result supports the ENDF/B-V value, we continue to use the latter cross sections.

The leakage of the bath was estimated from a transmission measurement. The counting rate of a modified "long" counter was observed with the bath empty and then filled with the solution. A value of 0.026 was obtained. The agreement with the calculated value of 0.020 is satisfactory in view of the complexity of the bath geometry and the fact that the transmission measurement was made at only one position.

The structural absorption correction was measured by repeating the experiment, both open and sample irradiations, with an added aluminum layer around the sample chamber. The added aluminum doubled the absorption effect. The drift tube and sample support could not be doubled in this way because of space limitations, and sample-in measurements were made for only samples Be \#2 and $\mathrm{Be} \# 4$. Comparisons of the measurements with theoretical results from the MCNP calculations are shown in Table 8 . Agreement is satisfactory in view on the uncertainties involved. These comparisons represent all the cases for which experimental tests could be made. 


\begin{tabular}{|c|c|c|}
\hline Effect & Experiment & MCNP Calculation \\
\hline Leakage (no sample) & $0.026 \pm 0.003$ & $0.0203 \pm 0.002$ \\
\hline Abs in Al (open) & $0.007 \pm 0.001$ & $0.008 \pm 0.001$ \\
\hline Abs in $A 1$ (Be \#2) & $0.016 \pm 0.002$ & $0.014 \pm 0.001$ \\
\hline Abs in $\mathrm{Al}$ ( $\mathrm{Be} \# 4)$ & $0.026 \pm 0.003$ & $0.020 \pm 0.001$ \\
\hline Parasitic Abs (no sample) & $0.136 \pm 0.014$ & $0.133 \pm 0.025$ \\
\hline
\end{tabular}

\section{EXPERIMENTAL RESULTS}

In the experimental program twenty-two irradiations were made with the open beam, three with Be \#1, 5 with Be \#2, four with Be \#3, and eleven with Be \#4. With the aluminum structure doubled, four irradiations were made with the open beam, two with Be \#2, and four with Be \#4. The alpha-normalized saturated activities of these runs, together with their statistical standard errors, are listed in Table 9 . The data have been corrected for the effects of concentration increase (maximum $0.6 \%$ change) and $(d, d)$ neutron contamination from deuterium deposited in the target (maximum $0.2 \%$ change). The latter effect was determined from a series of blank-target irradiations, in which the ${ }^{56} \mathrm{Mn}$ activity was normalized to the counting rate from the current integrator, rather than from the a-particle detector. 
TABLE 9. EXPERIMENTAL DATA

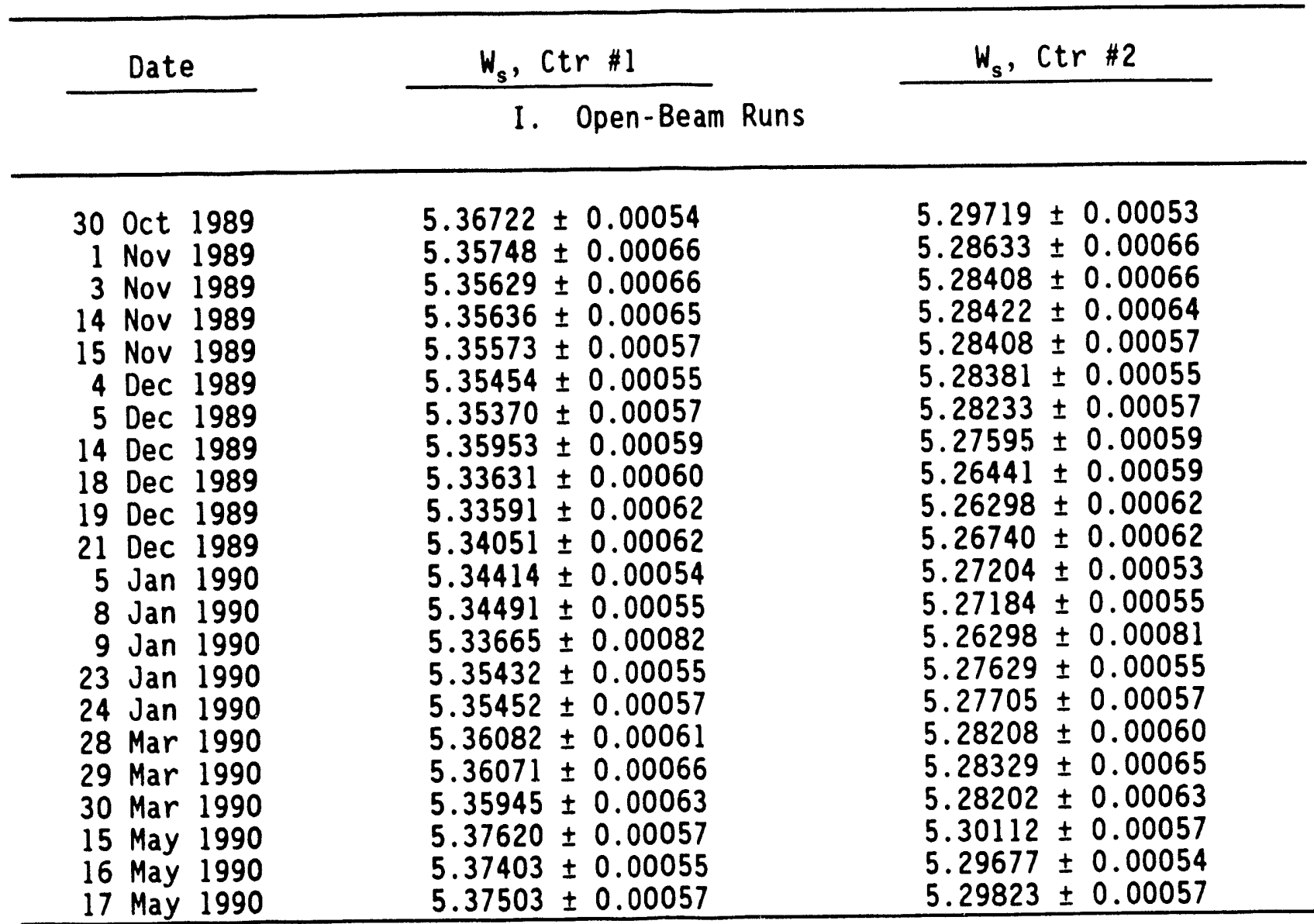

II. Be \#l Runs

$\begin{array}{lll}17 \text { Nov } 1989 & 7.44449 \pm 0.00071 & 7.34627 \pm 0.00071 \\ 20 \text { Nov } 1989 & 7.44366 \pm 0.00075 & 7.34254 \pm 0.00075 \\ 21 \text { Nov } 1989 & 7.44232 \pm 0.00069 & 7.34291 \pm 0.00068\end{array}$

II. Be \#2 Runs

\begin{tabular}{rll}
7 Nov 1989 & $10.33450 \pm 0.00097$ & $10.19778 \pm 0.00097$ \\
8 Nov 1989 & $10.32974 \pm 0.00133$ & $10.19456 \pm 0.00132$ \\
9 Nov 1989 & $10.33963 \pm 0.00087$ & $10.19963 \pm 0.00087$ \\
10 May 1990 & $10.34111 \pm 0.00075$ & $10.19493 \pm 0.00074$ \\
11 May 1990 & $10.34372 \pm 0.00088$ & $10.19709 \pm 0.00087$ \\
\hline
\end{tabular}


TABLE 9. EXPERIMENTAL DATA

\begin{tabular}{|c|c|c|}
\hline Date & $w_{s}, \operatorname{ctr} \# 1$ & $w_{s}, \operatorname{ctr} \# 2$ \\
\hline \multicolumn{3}{|c|}{ IV. Be \#3 Runs } \\
\hline $\begin{array}{rll}7 & \text { Dec } & 1989 \\
8 & \text { Dec } & 1989 \\
11 & \text { Dec } & 1989 \\
12 & \text { Dec } & 1989 \\
\end{array}$ & $\begin{array}{l}11.07342 \pm 0.00092 \\
11.07290 \pm 0.00084 \\
11.07103 \pm 0.00088 \\
11.07612 \pm 0.00085\end{array}$ & $\begin{array}{l}10.92469 \pm 0.00091 \\
10.92640 \pm 0.00083 \\
10.92236 \pm 0.00087 \\
10.93125 \pm 0.00086 \\
\end{array}$ \\
\hline \multicolumn{3}{|c|}{ V. Be \#4 Runs } \\
\hline $\begin{array}{r}28 \text { Dec } 1989 \\
29 \text { Dec } 1989 \\
3 \text { Jan } 1990 \\
15 \text { Jan } 1990 \\
16 \text { Jan } 1990 \\
18 \text { Jan } 1990 \\
19 \text { Jan } 1990 \\
3 \text { Apr } 1990 \\
23 \text { May } 1990 \\
24 \text { May } 1990 \\
25 \text { May } 1990\end{array}$ & $\begin{array}{l}11.37190 \pm 0.00102 \\
11.37035 \pm 0.00090 \\
11.37221 \pm 0.00098 \\
11.36733 \pm 0.00088 \\
11.36300 \pm 0.00100 \\
11.36715 \pm 0.00103 \\
11.36902 \pm 0.00091 \\
11.39469 \pm 0.00094 \\
11.41276 \pm 0.00074 \\
11.41349 \pm 0.00101 \\
11.41076 \pm 0.00077\end{array}$ & $\begin{array}{l}11.21725 \pm 0.00101 \\
11.21506 \pm 0.00089 \\
11.21667 \pm 0.00098 \\
11.21010 \pm 0.00087 \\
11.21138 \pm 0.00099 \\
11.20896 \pm 0.00102 \\
11.20811 \pm 0.00090 \\
11.23329 \pm 0.00093 \\
11.25153 \pm 0.00073 \\
11.24946 \pm 0.00101 \\
11.24860 \pm 0.00077\end{array}$ \\
\hline
\end{tabular}

VI. Open Beam with Extra Aluminum

\begin{tabular}{|c|c|c|}
\hline $\begin{array}{l}20 \text { Apr } 1990 \\
23 \text { Apr } 1990 \\
24 \text { Apr } 1990 \\
25 \text { Apr } 1990 \\
\end{array}$ & $\begin{array}{l}5.32667 \pm 0.00060 \\
5.33454 \pm 0.00065 \\
5.33318 \pm 0.00066 \\
5.33290 \pm 0.00062 \\
\end{array}$ & $\begin{array}{l}5.25058 \pm 0.00059 \\
5.25924 \pm 0.00064 \\
5.25636 \pm 0.00065 \\
5.25570 \pm 0.00062 \\
\end{array}$ \\
\hline \multicolumn{3}{|c|}{ VII. Be \#2 with Extra Aluminum } \\
\hline $\begin{array}{l}7 \text { May } 1990 \\
8 \text { May } 1990 \\
\end{array}$ & $\begin{array}{l}10.17227 \pm 0.00094 \\
10.19174 \pm 0.00073 \\
\end{array}$ & $\begin{array}{l}10.02786 \pm 0.00094 \\
10.04929 \pm 0.00072 \\
\end{array}$ \\
\hline \multicolumn{3}{|c|}{ VIII. Be \#4, With Extra Aluminum } \\
\hline $\begin{array}{r}27 \text { Apr } 1990 \\
30 \text { Apr } 1990 \\
1 \text { May } 1990 \\
3 \text { May } 1990\end{array}$ & $\begin{array}{l}11.11095 \pm 0.00094 \\
11.12775 \pm 0.00098 \\
11.12437 \pm 0.00086 \\
11.12066 \pm 0.00088\end{array}$ & $\begin{array}{l}10.94972 \pm 0.00094 \\
10.96898 \pm 0.00098 \\
10.96983 \pm 0.00085 \\
10.96409 \pm 0.00087\end{array}$ \\
\hline
\end{tabular}


From the experimental data of Table 9 the raw, or apparent, values of the multiplication were calculated. The results are summarized in Table 10. The measured apparent multiplication values are just the ratios of ${ }^{56} \mathrm{Mn} \alpha$ normalized saturated activities induced in the bath with and without the sample in place. No corrections for systematic effects have been made at this point. The quoted errors represent just the standard deviations of the replications of the experiment. The calculated values in Table 10 are the MCNP results. ${ }^{13}$ These values are the ratios of tallied capture events in the manganese in the bath. It is just the capture events that produce the ${ }^{56} \mathrm{Mn}$ activity that is counted in the experiment. The results are shown graphically in Figure 11. Agreement is excellent in all cases. The multiplication values calculated with the

TABLE 10 APPARENT MULTIPLICATION IN BULK BERYLLIUM

\begin{tabular}{|c|c|c|c|c|c|}
\hline \multirow{3}{*}{ Sample } & \multirow{3}{*}{ Experiment } & \multicolumn{4}{|c|}{ I. 14-MeV Neutrons } \\
\hline & & \multicolumn{4}{|c|}{ Calculation } \\
\hline & & $\mathrm{Y}-\mathrm{S} \mathrm{Be}$ & $C_{Y S} / E$ & ENDF/B-VI Be & $C_{V I} / E$ \\
\hline $\begin{array}{l}\mathrm{Be} \# 1 \\
\mathrm{Be}\end{array}$ & $\begin{array}{l}1.390 \pm 0.001 \\
1.928 \pm 0.001 \\
2.072 \pm 0.002 \\
2.127 \pm 0.001 \\
\end{array}$ & $\begin{array}{l}1.382 \pm 0.009 \\
1.902 \pm 0.011 \\
2.037 \pm 0.012 \\
2.077 \pm 0.015 \\
\end{array}$ & $\begin{array}{l}0.994 \\
0.987 \\
0.983 \\
0.976 \\
\end{array}$ & $\begin{array}{l}1.360 \pm 0.007 \\
1.870 \pm 0.009 \\
2.013 \pm 0.009 \\
2.087 \pm 0.009 \\
\end{array}$ & $\begin{array}{l}0.978 \\
0.970 \\
0.972 \\
0.981 \\
\end{array}$ \\
\hline \multicolumn{6}{|c|}{ II. ${ }^{252} \mathrm{Cf}$ Source } \\
\hline Sample & Experiment & Calc, Y-S Be & $C_{Y S} / E$ & & \\
\hline $\begin{array}{l}\mathrm{Be} \# 1 \\
\mathrm{Be} \# 2 \\
\mathrm{Be} \# 3 \\
\mathrm{Be} \# 4\end{array}$ & $\begin{array}{l}1.036 \pm 0.002 \\
1.020 \pm 0.002 \\
0.979 \pm 0.002 \\
0.906 \pm 0.002\end{array}$ & $\begin{array}{l}1.038 \pm 0.009 \\
1.021 \pm 0.009 \\
0.987 \pm 0.009 \\
0.907 \pm 0.008\end{array}$ & $\begin{array}{l}1.002 \\
1.001 \\
1.008 \\
1.001\end{array}$ & & \\
\hline
\end{tabular}

ENDF/B-VI beryllium data are only two to three per cent lower than those calculated with the Young-Stewart data, even though the $(n, 2 n)$ cross sections 
are about 15\% lower. This is because the absorption cross sections are also lower for the ENDF/B-VI data.

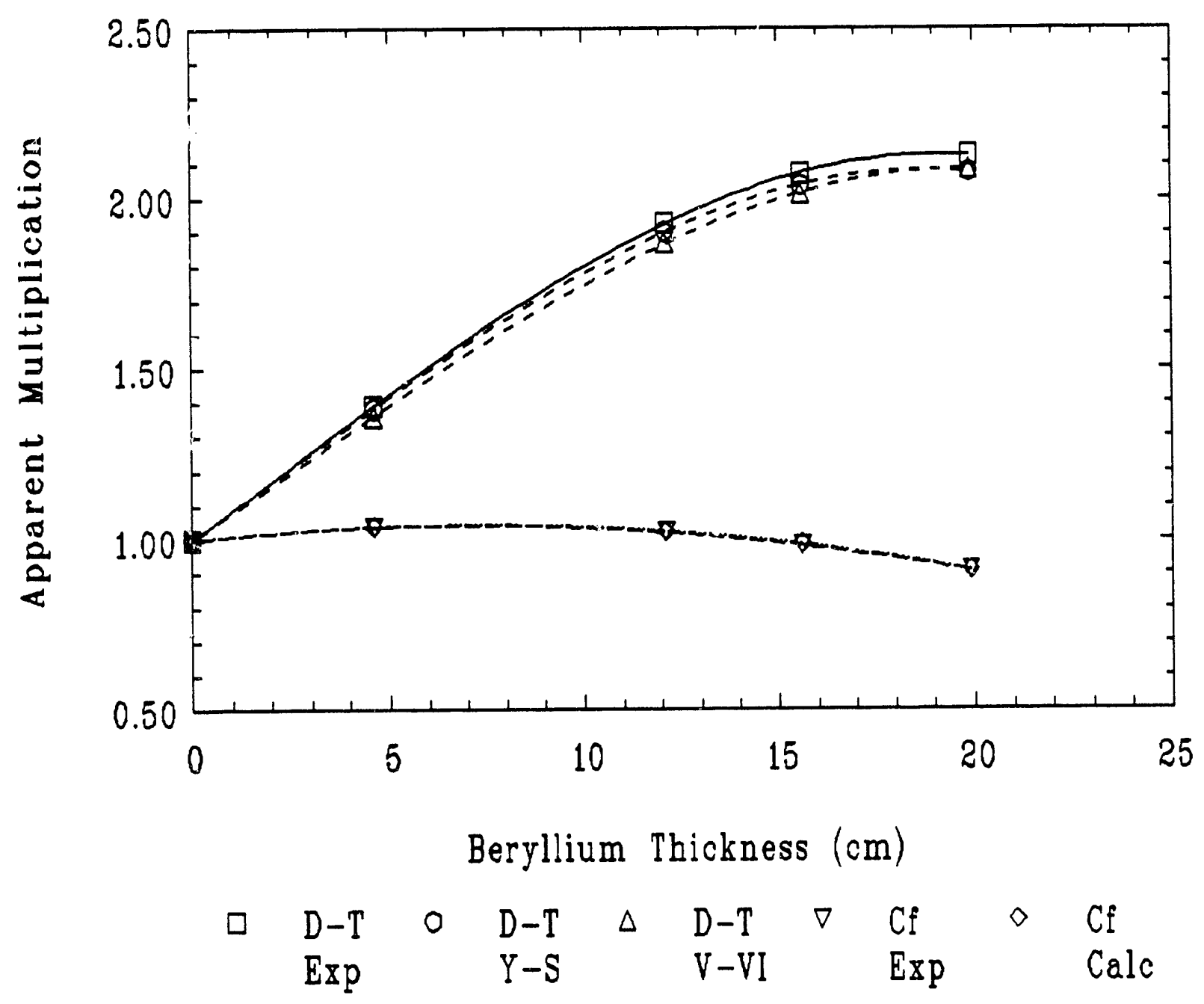
samples

Figure 11. Apparent multiplication of $14-\mathrm{MeV}$ neutrons in beryllium

Also shown in Table 10 are the raw multiplication values measured for a ${ }^{252} \mathrm{Cf}$ source. The irradiations using the ${ }^{252} \mathrm{Cf}$ source have a dual purpose. Since the manganese bath systematic effects have heen studied in more detail for fission neutron sources than for any other neutron source, the ${ }^{252} \mathrm{Cf}$ model 
serves as a benchmark test for the MCNP calculations. Further, since $(n, 2 n)$ multiplication is much lower for a fission source than for a 14-MeV source, the ${ }^{252} \mathrm{Cf}$ irradiations display the effects of neutron absorption in beryllium. A measured multiplication value significantly lower than the calculated value could indicate that impurities are present in the beryllium in quantities higher than those expected. The close agreement between calculation and experiment in this case indicates that the beryllium impurities are correctly accounted for.

The true values for multiplication in beryllium are obtained by applying the corrections listed in Tables 5 and 6 . The corrected multiplication values for the four Be samples are shown in Table 11. The values shown represent the net corrected multipication in each sample, including the effects of neutrons returning from the bath to tie beryllium. The net corrected values of multiplication in the bulk beryllium samples are shown graphically in Figure 12 .

TABLE 11. NET CORRECTED MULTIPLICATION IN BULK BERYLLIUM, 14-MEV NEUTRONS

$$
\text { Sample Experiment }
$$

Calculation

\begin{tabular}{|c|c|c|c|c|c|}
\hline & & $Y-S B e$ & $C_{Y S} / E$ & ENDF/B-VI Be & $C_{V l} / E$ \\
\hline $\mathrm{Be} \# 1$ & $1.311 \pm 0.035$ & $1.304 \pm 0.001$ & 0.995 & $1.288 \pm 0.001$ & 0.982 \\
\hline $\mathrm{Be} \# 2$ & $1.764 \pm 0.043$ & $1.738 \pm 0.003$ & 0.985 & $1.715 \pm 0.003$ & 0.972 \\
\hline $\mathrm{Be} \# 3$ & $1.904 \pm 0.046$ & $1.873 \pm 0.004$ & 0.984 & $1.850 \pm 0.003$ & 0.972 \\
\hline $\mathrm{Be} \# 4$ & $1.988 \pm 0.048$ & $1.964 \pm 0.004$ & 0.988 & $1.948 \pm 0.004$ & 0.980 \\
\hline
\end{tabular}




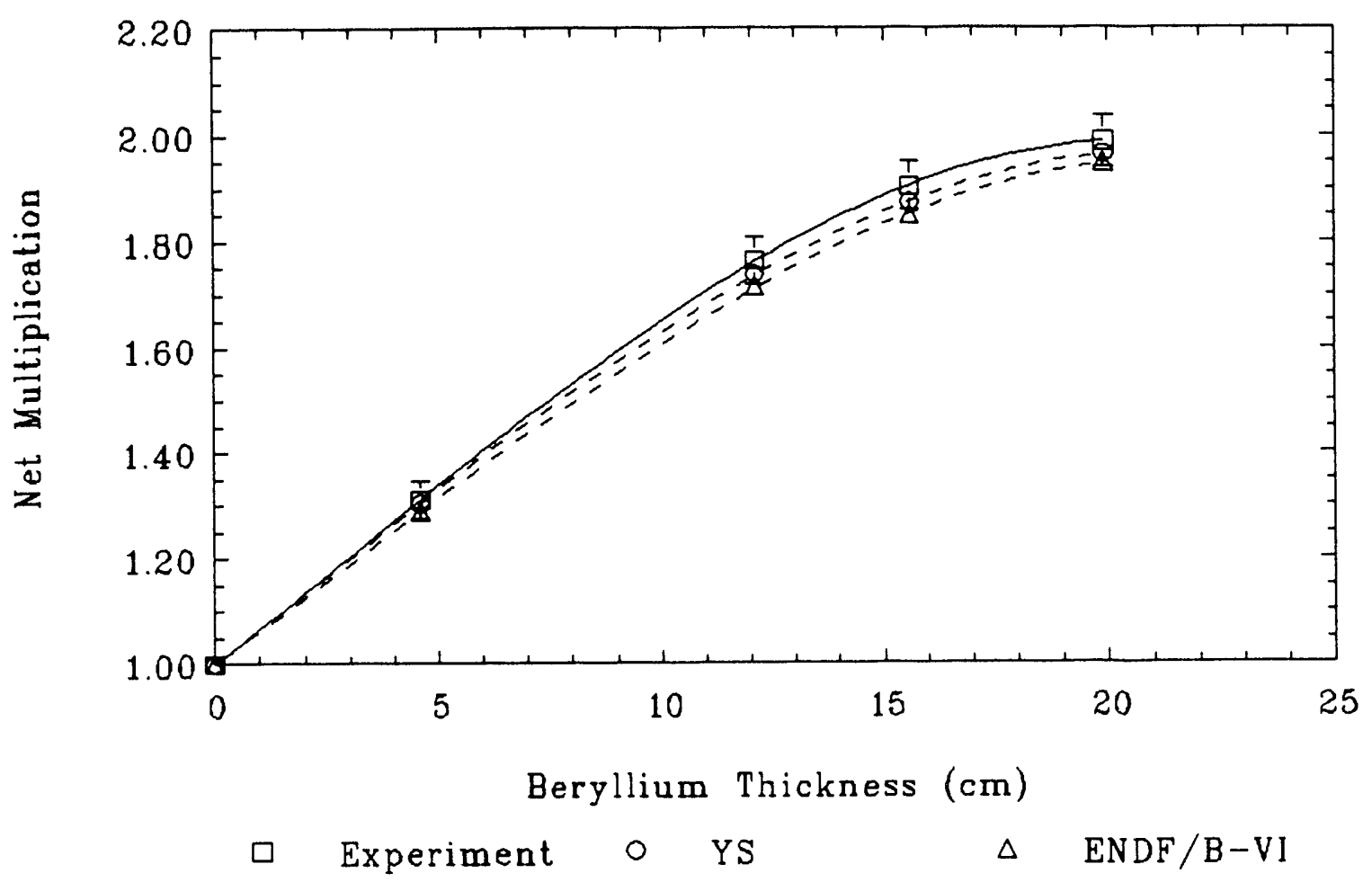

Figure 12. Net corrected multiplication in beryllium.

\section{CONCLUSIONS}

The multiplication of $14-\mathrm{MeV}$ neutrons in bulk beryllium has been measured for four thicknesses of beryllium, ranging from $4.6 \mathrm{~cm}$ to $19.9 \mathrm{~cm}$. The measured values have uncertainties ranging from $2.4 \%$ to $2.7 \%$, and are in excellent agreement with the predictions based upon microscopic data. Residual differences may be at least partially due to uncertainties in auxiliary data such as the ${ }^{16} 0(n, \alpha){ }^{13} \mathrm{C}$ cross section. We see no evidence of a substantial calculation-experiment discrepancy such as that mentioned by cloth et al. ${ }^{1}$ and other experimenters. Indeed, whereas the nature of the supposed discrepancy was that measured values of the multiplication were lower than calculated, our measured values are slightly higher than those calculated using data from 
either of the two beryllium evaluations considered. Agreement with experiment is slightly better for the Young-Stewart evaluation than for the ENDF/B-VI data. However, the two evaluations differ very little in net multiplication effect, and both agree well with our measurements. Either data set can be used with confidence in predicting the neutron multiplication of neutrons in fusion reactor blankets containing beryllium. 


\section{REFERENCES}

1. P. CLOTH et al., "Neutron Multiplication Effect of CTR Blankets Containing Beryllium," Proc. 9th Symp. Fusion Technology, Garmisch-Partenkirchen, FRG, June 14-18, 1978, Pergamon Press, 1977.

2. T. K. BASU et al., "Neutron Multiplication Studies in Beryllium for Fusion Reactor Blankets," Nucl. Sci. Engr. 70, 1979, p. 309.

3. V. R. NARGUNDKAR, T. K. BASU, and 0. P. JONEJA, "Reanalys is of Neutron Multiplication Measurements in Thick Beryllium and Graphite Assemblies for 14-MeV Neutrons," Fusion Technology 12, 1987, p. 380.

4. R. S. HARTLEY, "Neutron Multiplication in Beryllium, "Dissertation, The University of Texas at Austin, Dec. 1987.

5. N. E. HERTEL, J. W. DAVIDSON, and R. S. HARTLEY, "Analys is of the Texas Beryllium Neutron Multiplication Experiment," 8th Topical Meeting on the Technology of Fusion Energy, Paper 6-NUC-5, Salt Lake City, Utah, Oct. 9-13, 1988 .

6. C. WONG et al., "Measurements and Calculations of the Leakage Multiplication from Hollow Beryllium Spheres," Fusion Technology 8, 1985, p. 1165.

7. Bulk Interim Reports 2-11, COPE-2338, -2514, -2532, -2579, -2752, -2753, COPP-726, -784, -816, Lawrence Livermore National Laboratory, 1955-56.

8. Y. CHEN et. al., "Experiment of Neutron Multiplication in Beryllium," Nuclear Data for Neutron Multiplication in Fusion-Reactor First-Wall and Blanket Materials, Chengdu, China, Nov. 19-21, 1990.

953 J. R. SMITH, S. D. REEDER, and R. J. GEHRKE, Neutron Multiplicities of ${ }^{252} \mathrm{Cf}$ and the Fissile Nuclei, EPRI NP-3436, 1984.

10. E. J. Axton, "Intercomparison of Neutron-Source Emission Rates (19791984 )," Metrologia 23, 1987, p. 129.

11. C. WONG et al., "Livermore Pulsed Sphere Program: Program Summary Through July 1971," UCRL-5114. Rev. 1, 1972.

12. D. M. GILLIAM, "An Absolute Determination of the ${ }^{235} \mathrm{U}$ Fission Cross Section at $964 \mathrm{KeV}, " \mathrm{Ph}$. D. Dissertation, University of Michigan, 1973.

13. J. W. DAVIDSON, "Calculational Analysis of the INEL Beryllium Multiplication Experiment," Paper 6E-14, Ninth Topical Meeting on the Technology of Fusion Energy, Oak Brook, IL, Oct 7-11, 1990.

14. P. G. YOUNG and L. STEWART, Evaluated Data for $n+B e^{9}$ Reactions, LA$7932-M S, 1979$. 
15. K. E. Larsson, "The Use of the ${ }^{3} T(d, n)^{4} H e$ Reaction for a Comparison of Some Methods for the Absolute Measurement of a Fast Neutron Flux, "Arkiv för Fysik, Bd $9 \mathrm{Nr} 18,1955, \mathrm{p} .293$.

16. A. F. BIELAJEW and D. W. O. ROGERS, "RALPHA, " PXNR-2474, 1978.

17. J. R. Smith and J. J. King, "Neutron Multiplication in Bulk Beryllium," Ninth Topical Meeting on the Technology of Fusion Energy, Oak Brook, IL, Oct 7-11, 1990 .

18. P. G. YOUNG, private communication 


\section{APPENDIX}

The following pages contain a description by R. C. Little and R. E. Seamon, of Los Alamos National Laboratory, of their conversion of the MCNP Monte Carlo code to accommodate the use of the ENDF/B-VI beryllium cross section data. 


$$
\text { A-2 }
$$




\author{
A Description of an ENDF/B-VI 'Be Data Library for MCNP \\ and \\ A Modified Version of MCNP to Use the New Data \\ by \\ Robert C. Little and Robert E. Seamon \\ Radiation Transport Group X-6 \\ Los Alamos National Laboratory, Los Alamos New Mexico 87544
}

\title{
INTRODUCTION
}

The MCNP Monte Carlo radiation transport code (Ref. 1) has always taken advantage of the most modern evaluated nuclear data. Most recently, the primary source of evaluated nuclear data for MCNP has been ENDF/B-V (Ref. 2). Although the format (Ref. 3) for ENDF/B-V allowed correlated energy-angle distributions of secondary neutrons, those File 6 possibilities were never implemented or used. Only the implicit secondary energy-angle correlation for elastic and discrete-inelastic scattering was used. The secondary energy distributions and secondary angular distributions of neutrons from all other reactions (e.g., $(n, 2 n)$ and fission) were always completely uncorrelated. This situation has changed significantly as a result of a more general format description referred to as ENDF-6 (Ref. 4) available for ENDF/B-VI.

The ENDF- 6 format introduces a completely revised and expanded File 6 for evaluations. The purpose of File 6 is to allow representation of reaction products in energy and angle. In particular, evaluators are to use file 6 when the energy and angular distributions of the emitted particle must be coupled. The production cross section (in barns/steradian) for a given reaction product is

$$
\sigma_{i}\left(\mu, E, E^{\prime}\right)=\sigma(E) y_{i}(E) f_{i}\left(\mu, E, E^{\prime}\right) / 2 \pi
$$

where $i$ denotes the reaction product, $E$ is the incident energy, $E^{\prime}$ is the energy of the product emitted with cosine $\mu, \sigma(E)$ is the interaction cross section, $y_{i}$ is the product yield or multiplicity, and $f_{i}$ is the normalized distribution so that

$$
\int d E^{\prime} \int d \mu f_{i}\left(\mu, E, E^{\prime}\right)=1
$$

Several different laws are available to describe $f_{i}\left(\mu, E, E^{\prime}\right)$ in file 6 . One of the available laws (Law 7 ) is the laboratory angle-energy law. The data for Law 7 are sorted according to $\left(E, \mu, E^{\prime}\right)$; i.e., the secondary energy is a function of the secondary scattering angle. Both are functions of the incident energy. 
The ENDF/B-VI evaluation of ${ }^{9} \mathrm{Be}$ (Ref 5 ) takes advantage of File 6-Law 7 to represent secondary neutrons from the $(n, 2 n)$ reaction. The objectives of the current work are to define a new MCNP data-library format for this Law 7 , to process the ENDF/B-VI evaluation of ${ }^{9} \mathrm{Be}$ into that new data-1ibrary format, to modify MCNP to read and correctly sample from the Law 7 data, to validate the previous steps, and to make the package available to individuals at the LOS Alamos Nation Laboratory for MCNP analysis of ongoing experiments.

\section{NEW DATA-LIBRARY FORMAT}

The format of MNCP data libraries is described in detail in Appendix $F$ of Ref 1 . Separate portions of the libraries exist for angular distributions of secondary neutrons (see pates 505-506 of Ref 1) and for energy distributions of secondary neutrons (see pages 506-513 of Ref. 1). As described in the Introduction, the secondary distributions represented on the libraries up to now have been uncorrelated. (The exceptions are elastic scattering and discrete-level inelastic scattering. In both cases, for a particular incident neutron energy, each secondary scattering cosine uniquely determines a secondary energy.) Obviously, the advent of ENDF-6 generalized formats requires new MCNP data-library formats as well.

The strategy employed to define an MCNP data-1ibrary format to represent Law 7 data is as follows: (1) Secondary neutron angular distributions are generated from the Law 7 data and provided in the AND Block (Table F.12 of Ref. 1). There is no change from the current procedures in which all evaluated angular distributions are processed into 32 equally-likely secondary cosine bins. This method is appropriate for Law 7 , because secondary angular distributions are a function of incident energy only. (2) A new format is defined for the DLW Block (Table F.14 of Ref. 1). The new MCNP law is called Law 67 (for ENDF/B File 6 -Law ㄱ). The format for MCNP Law 67 is fully defined in Table I, which is similar to parts a-j of Table F.14 of Ref. 1.

\section{PROCESSING OF ENDF/B-VI ${ }^{9} B E$}

Generally, ENDF/B data are processed into a format appropriate for MCNP by the NJOY code (Ref. 6). In this section we describe a somewhat nonstandard use of NJOY for the current problem.

The ENDF/B-VI evaluation of ${ }^{9}$ Be was made available on the Common File System (CFS) at.LoS Alamos by R. E. MacFarlane, Group T-2, as MAT-425 on /ENDF/6/NEUTRON/BE/9. To use effectively the current production version of NJOY, the evaluation was re-cast in ENDF/B-V format. ENDF/B File 6 angular distribution data were translated into an identical, but more traditional, File 4 representation using the code GMG. For the purpose of the initial NJOY processing, the ENDF/B File 6 energy distribution data were replaced with "place-holder" File 5 data generated in code MAKD, designed to represent accurately the neutron energy deposition. The following modules of NJOY were then executed to produce a preliminary MCNP data library: MODER, RECONR, BROADR, HEATR, and ACER.

Using the utilities COPY and EDIT, the File 6-Law 7 data were incorporated into the preliminary MCNP ACE library created by NJOY. The 
secondary energy distribution data were added in the format described in Table I. Additional information, such as average secondary energies, was obtained from the CKHOW code. It is anticipated that the functions of GMG, MAKD, and CKHOW will ultimately be added to NJOY as part of a comprehensive upgrade of NJOY and MCNP associated with ENDF/B-VI. (It should be understood that all this work has been done only for ${ }^{9} \mathrm{Be}$, because File 6-Law 7 is used for this isotope and this isotope alone.) The final ENDF/B-VI 'Be MCNP data library (in Type 3 ACE format) was stored on CFS as /076997/MYREDSTUFF/BEST1.

\section{MCNP MODIFICATIONS}

A patch was written to Version 4.1 of MCNP (described in Ref. 7) to allow the code to read and sample from the new MCNP Law 67 data described above. The patch modifies MCNP Subroutine ACECAS, which is the routine that samples the energy of a secondary particle from the MCNP law data. The patch is available on CFS as /MYQEDSTUFF/BE9/PATCHBE9.

When the modified ACECAS recognizes the need to sample from MCNP Law 67, the routine first calls ACECOS to sample the secondary scattering cosine. Then the secondary energy is sampled as a function of the sampled secondary scattering cosine. If the sampled value of the secondary scattering cosine lies between two cosine values at which secondary energy distributions are tabulated, a random number is used to select one or the other data set to sample from. When the incident energy is between two energy values at which secondary distributions are tabulated (and histogram interpolation is not invoked), a scaling method is employed, similar to that described in Section VI of Ref. 8. A secondary energy is sampled from the data provided for both incident energies; the scaling formalism is then used to determine the actual secondary energy.

The patched executable version of MCNP (for CRAY Y-MPS operating under (TSS) is available on CFS as /MYREDSTUFF/BE9/MCNPBE9. Note that this code does not currently support the MCNP point detector or DXTRAN capabilities when used in conjunction with MCNP Law 67.

\section{VALIDATION OF DATA LIBRARY / CODE PACKAGE}

There were three major aspects of our validation of the data library / code package: (1) differential and integral testing of the "traditional" portions of the data library, (2) differential and integral testing of the new (i.e., Law 67) portion of the data library, and (3) testing of various aspects of the patched version of MCNP using the new ENDF/B-VI ${ }^{9} \mathrm{Be}$ data library. In each case, the goal of our validation effort was to ensure that the package reproduced the intentions of the evaluators. Each aspect of our validation effort will now be described briefly.

Differential and integral testing of the "traditional" (i.e., non-Law 67) portion of the data library was accomplished with the MRKACR, MARK (Ref. 9), XSFICHE (Ref. 10), and XDATAP (Ref. 11) codes. MRKACR and MARK were used to compare integral, group-averaged cross sections for each reaction from the MCNP library and the original ENDF library, respectively. XSFICHE provided interpreted microfiche listings of the data found on the MCNP cross-section 
library. Finally, XDATAP was used to produce differential plots from the MCNP library and from the original ENDF library. The data testing efforts described in this paragraph led, in all cases, to satisfactory conclusions.

To ensure correctness of the Law 67 data on the MCNP library, a new code, INF067, was written. The code reads the MCNP data library and provides an interpreted listing of all of the Law 67 data found. The results therefrom are voluminous for the current case, with triplets of data (energy, probability density function, and cumulative density function) for as many as 91 secondary energy points, each for 21 scattering cosines, each for 17 incident energies (from 2.01 MeV to $20.0 \mathrm{MeV}$ ). Despite the volume of data, the output from INF067 has allowed us to compare data values found on the MCNP library with those from the original ENDF/B-VI File 6-Law 7 tabulation. In all cases compared, agreement was obtained.

The most demanding testing of the data library / MCNP combination was carried out using the patched version of MCNP with the ENDF/B-VI ${ }^{9} \mathrm{Be}$ data library. First, a significant amount of dynamic debugging was performed to check the flow of the code when sampling from Law 67 data in the modified ACECAS subroutine. In all cases, the code performed as expected. Second, a series of simple MCNP calculation were performed, in which the source energy in a pure ${ }^{9} \mathrm{Be}$ problem was $E_{p}$, and a neutron cutoff energy was set at $E_{n}-\varepsilon$, with $e=1.0 \times 10^{-6}$. The goal' was to allow MCNP to repeatedly sample secondary energies from the $(n, 2 n)$ reaction. By picking $E_{p}$ equal to values of incident neutron energy at which secondary data were tabulated, it was possible to compare average energies sampled by MCNP to average energies computed from integrations of the actual ENDF/B-VI data. Results confirmed our conclusion that the ENDF/B-VI File 6-Law7 data have been correctly interpreted and sampled by MCNP.

\section{AVAILABILITY OF DATA LIBRARY / CODE PACKAGE}

The ${ }^{9} \mathrm{Be}$ data library and modified MCNP have been made available to J. W. Davidson of Group A-3 at Los Alamos. The procedure for using the package is as follows:

MASS GET/MYREDSTUFF/BE9/MCNPBE9 (executable MCNP)

MASS GET/MYREDSTUFF/BE9/XSDIR (updated directory file)

MCNPBE9 INP $=\ldots$.

The ZAID of the ENDF/B-VI 'Be library is $4009.60 \mathrm{C}$. Finally, the user should note that the $(n, 2 n)$ reaction is given by $M T=16$. This information is required MCNP tallies using the FM feature.

\section{SUMMARY}

A new MCNP data-library format has been defined to allow correlated energy-angle data from ENDF-6 File 6 -Law 7 evaluations. The ENDF/B-VI evaluation of ${ }^{\circ} \mathrm{Be}$ has been processed into that format. MCNP has been modified to correctly sample from the new data. The data library / code package has undergone significant testing to validate the work done to satisfy the tasks described above. The entire package has been made available to others at Los

$$
\text { A-6 }
$$


Alamos to allow further MNCP analys is of earlier ${ }^{9}$ Be multiplication experiments. 


\section{REFERENCES}

1. J. F. Briesmeister, Editor, "MCNP - A General Monte Carlo Code for Neutron and Photon Transport, Version 3A," Los Alamos National Laboratory manual LA-7396-M, Rev. 2 (September 1986).

2. R. Kinsey, Compiler, "ENDF-201 ENDF/B Summary Documentation," Brookhaven National Laboratory report BNL-NCS-17541 (ENDF-201) 3rd Edition (ENDF/B-V) (UC-80) (July 1979).

3. D. Garber, C. Dunford, and S. Pearlstein, "ENDF-102 Data Formats and Procedures for the Evaluated Nuclear Data File, ENDF," Brookhaven National Laboratory report BNL-NCS-50496 (ENDF-102) (October 1975).

4. P. F. Rose and C. L. Dunford, Editors, 'ENDF-102 Data Formats and Procedures for the Evaluated Nuclear Data File ENDF-6," Brookhaven National Laboratory informal report BNL-NCS-44945 (July 1990).

5. K. J. Howerton and M. H. MacGregor, "The LLL evaluated Nuclear Data Library (ENDL): Descriptions of Individual Evaluations for $Z=0-98$," Lawrence Livermore Laboratory report UCRL-50400, Vo1. 15, Part D. Rev. 1 (May 17, 1978).

6. R. E. MacFarlane, D. W. Muir, and R. M. Boicourt, "The NJOY Nuclear Data Processing System, Volume I: User's Manual," Los Alamos National Laboratory manual LA-9303-M, Vol. I (ENDF-324)(May 1982).

7. J. S. Hendricks, "MCNP4.1," Los Alamos National Laboratory internal memorandum X-6:JSH-90-524 to Distribution (September 27, 1990).

8. R. J. Howerton, R. E. Dye, P. C. Giles, J. R. Kimlinger, S. T. Perkins, and E. F. Plechaty, "OMEGA:A Cray 1 Executive Code for LLNL Nuclear Data Libraries," Lawrence Livermore National Laboratory report UCRL-50400, Vol. 25 (August 1983).

9. R. E. Seamon, "The MARK and MRKACR Codes," Los Alamos National Laboratory internal memorandum X-6:RES-87-182 to Distribution (March 26, 1987).

10. R. C. Little, "Cross Section Processing Codes on the CRAY," Los Alamos National Laboratory internal memorandum X-6:RCL-85-415 to R. E. Seamon and H. M. Fisher (August 13, 1985).

11. H. M. Fisher, "XDATAP," Los Alamos National Laboratory report LA11155-MS (March 1988). 
Table I

Format Description of MCNP DLW Block Law 67

$\operatorname{Law}_{i}=67 \quad$ Laboratory Energy-Angle Law (from ENDF-6 File 6 Law 7)

Location Parameter

$\operatorname{LDAT}(1) \quad$ NR

$\begin{array}{ll}\operatorname{LDAT}(2) & \mathrm{NBT}(\mathrm{I}), I=1, N R \\ \operatorname{LDAT}(2+N R) & \mathrm{INT}(I), I=1, N R\end{array}$

$\begin{array}{ll}\operatorname{LDAT}(2+2 * N R) & N E \\ \operatorname{LDAT}(3+2 * N R) & \mathrm{EIN}(\mathrm{I}), I=1, N E\end{array}$

LDAT $(3+2 \star N R+N E) \quad \operatorname{LEIN}(I), I=1, N E$

Description

Number of interpolation

regions

ENDF interpolation

parameters. If $\mathrm{NR}=0$, NBT and

INT are omitted and linearlinear interpolation is used.

Number of incident energies

Incident energies

Location of data for each

incident energy (relative to

JXS(11) or JXS(19))

Data for EIN (1) (let $K=3+2 * N R+2 * N E)$ :

$\operatorname{LDAT}(K) \quad$ INTMU

Interpolation parameter between secondary cosines (INTMU $=1$ is histogram, INTMU =2 is linear-linear)

Number of secondary cosines Secondary cosines

$\begin{array}{ll}\operatorname{LDAT}(K+1) & \mathrm{NMU} \\ \operatorname{LDAT}(K+2) & \mathrm{XMU}(I), I=1, N M U\end{array}$

Location of data for each

$\operatorname{LDAT}(K+2+N M U) \quad \operatorname{LMU}(I), I=1$, NMU

secondary cosine (relative to

JXS(11) or JXS(19))

$\operatorname{LDAT}(\mathrm{J})$

Data for $X M U(1)$ (let $J=K+2+2 * N M U)$ :

Interpolation parameter between secondary energies

(INTEP $=1$ is histogram, INTEP =2

is linear-linear)

$\begin{array}{ll}\operatorname{LDAT}(J+1) & N P E P \\ \operatorname{LDAT}(J+2) & \operatorname{EP}(I), I=1, N P E P \\ \operatorname{LDAT}(J+2+N P E P) & P D F(I), I=1, N P E P \\ \operatorname{LDAT}(J+2+2 * N P E P) & \operatorname{CDF}(I), I=1, N P E P\end{array}$

Number of secondary energies

Secondary energy grid

Probability density function

Cumulative density function

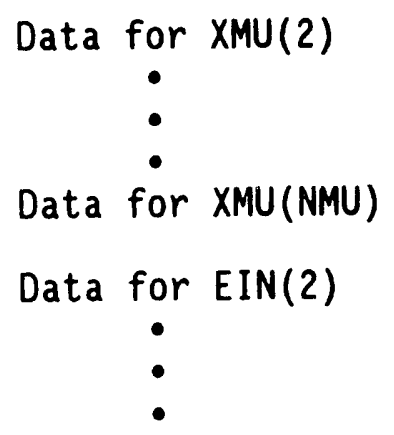


Data for EIN(NE)

:

A- 10 

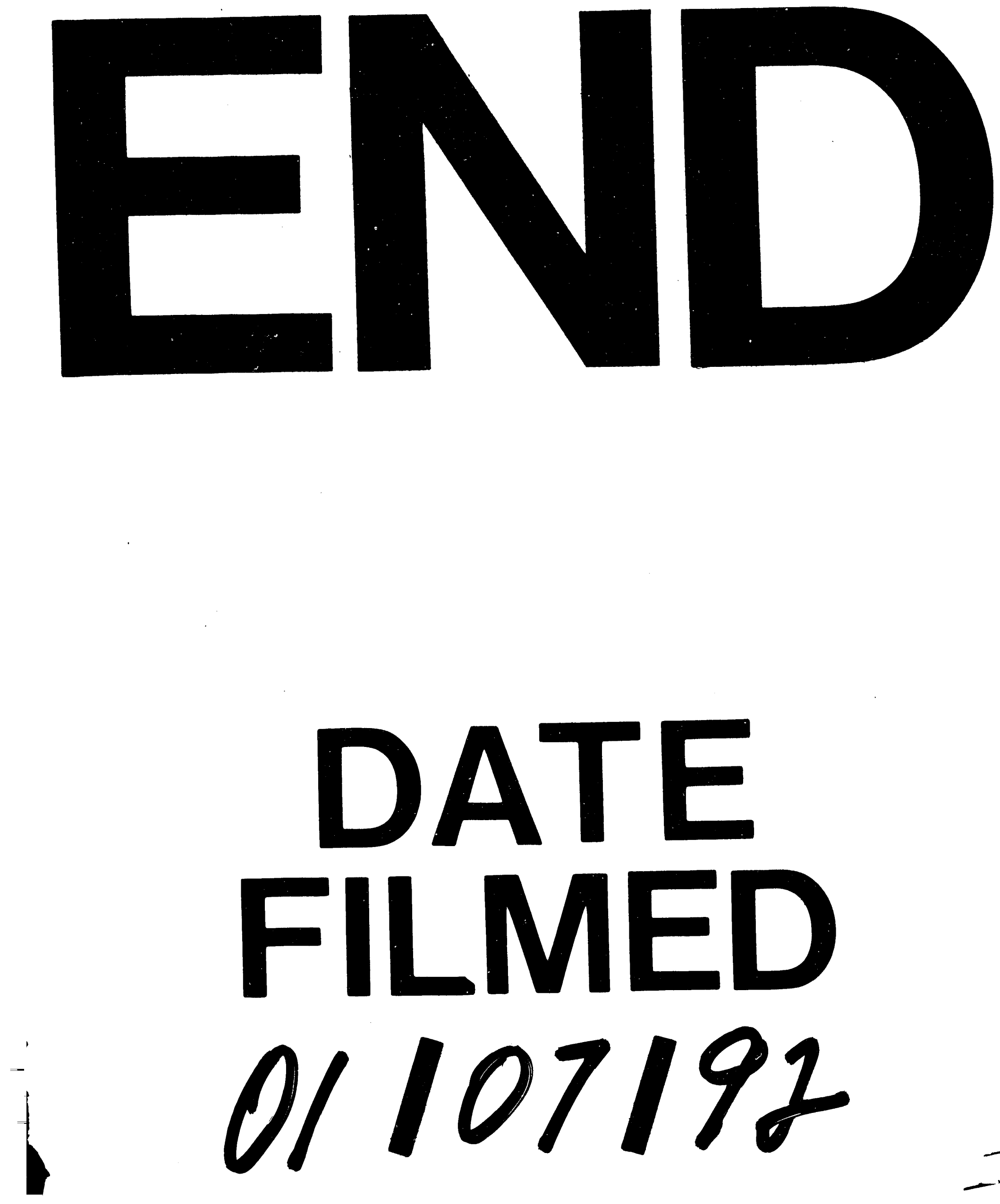

T' 
